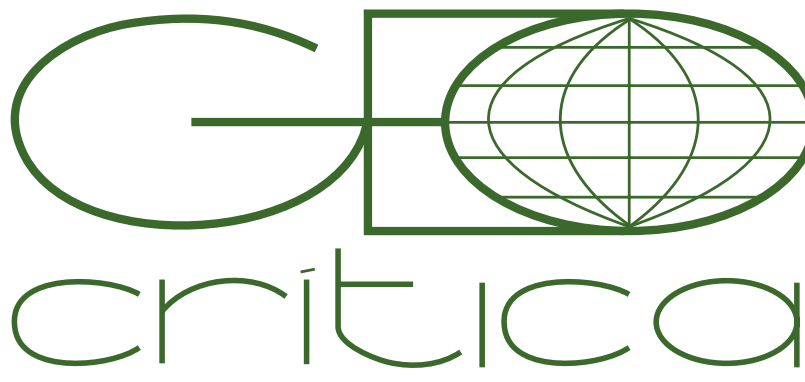

Scripta Nova

Revista Electrónica de Geografía y Ciencias Sociales Universitat de Barcelona

15 de junio de 2018

\title{
GEOGRAFÍAS DE LA CONTENCIÓN: EL ROL DE LAS POLÍTICAS DE ESCALA BARRIAL EN EL CHILE NEOLIBERAL
}

\author{
Verónica Tapia Barría \\ Universidad Católica del Maule, Chile \\ veronicatapiabarria@gmail.com
}

Recibido: 18/10/2017; Devuelto para correcciones: 15/12/2017; Aceptado: 8/3/2018

\section{Geografías de la contención: el rol de las políticas de escala barrial en el Chile neoliberal (Resumen)}

El análisis de las políticas de escala barrial evidencia un protagonismo de estas iniciativas a partir de la década de los noventa, relacionado con la reestructuración neoliberal global. En este marco, Chile es un caso representativo, pues las políticas de escala barrial se implementan al término de la dictadura cívico-militar que instaura los principios neoliberales, los cuales serán fortalecidos por los gobiernos posteriores. Considerando elementos de la Economía Política Cultural y los conceptos de humanización del neoliberalismo, expoliación y esquilmo el artículo plantea que las políticas de escala barrial cumplen un relevante rol ideológico, en tanto desplazan, controlan y delimitan los conflictos derivados de la implementación de políticas urbanas neoliberales, evidenciados en la pobreza y desigualdades urbanas. Específicamente propone la figura de la contención -como consuelo, contenedor y control- para entender el rol de las políticas de escala barrial en el Chile neoliberal.

Palabras clave: Barrio, contención, neoliberalismo

\section{Geographies of containment: the role of neighbourhood policies in the neoliberal Chile (Abstract)}

The analysis of neighborhood-scale policies has assumed a leading role within these initiatives since the 1990s, according to global neoliberal restructuring. In this framework, Chile is a representative case, since neighborhood-scale policies are implemented the end of the civic-military dictatorship, establishing neoliberal principles which will be strengthened by subsequent governments. Taking elements from the Cultural Political Economy and the concepts of humanization of neoliberalism, spoliation and depletion into account, this article proposes that neighborhood scale policies fulfill a relevant ideological role, as they displace, control and delimit the conflicts derived from the implementation of neoliberal urban policies, that affect poverty and urban inequalities. Specifically, the figure of containment -as consolation, container and control- is proposed to understand the role of neighborhood-scale policies in neoliberal Chile

Key words: Neighbourhood, containment, neoliberalism 
Hacia la década de los noventa el barrio adquiere un protagonismo central en el diseño de políticas urbanas, así, desde el punto de vista técnico el barrio se erige como foco que permite distribuir servicios o articular intervenciones de rehabilitación, regeneración y revitalización urbanas. Pero también sería protagonista desde una perspectiva política, pues el barrio se consigna como una escala estratégica a partir de la cual los gobiernos levantarían sus agendas respecto a principios como cohesión social, capital social y ciudadanía ${ }^{1}$.

Esto pues la persistencia e incluso el aumento de la pobreza, la desigualdad y las consecuentes tensiones sociales serán un hecho conocido y finalmente asumido por los gobiernos, lo que implica que la atención se vuelve a poner en estos problemas que a menudo tenían su mayor expresión en las áreas urbanas y ciudades ${ }^{2}$. Es en este contexto que los gobiernos requieren enfrentar con políticas específicas estos problemas, de modo que Europa (Unión Europea y Estados miembros) y Estados Unidos lideran el proceso de diseño de una nueva generación de políticas urbanas donde el barrio cobra una importancia fundamental ${ }^{3}$.

La literatura sugiere algunas razones para este hecho ${ }^{4}$ : el barrio ha sido considerado como el bloque básico a partir del cual mantener la cohesión social (supuestamente en "crisis"), evidente saturación de pobreza y desigualdad en zonas de las grandes ciudades y la consideración del barrio como "el" lugar de la comunidad local. También, existe una razón política: en el actual contexto global los gobiernos y los diseñadores de políticas públicas no son capaces de controlar los efectos del capitalismo global por lo cual el barrio es la escala más accesible y posible de intervenir. Finalmente, el enfoque en el barrio ofrecería una atractiva (¿y barata?) alternativa para responder a la exclusión social y la regeneración urbana a través del fortalecimiento del capital social y el gobierno local.

Así, las políticas de enfoque barrial se basan en dos argumentos conducentes a acciones específicas. El primer argumento es que si se fomenta o fortalece la cohesión social al nivel de barrio ello tendrá consecuencias positivas al nivel general de la sociedad, es decir, es una vía para la resolución de una "crisis de la cohesión social". Y segundo, que si las comunidades excluidas y pobres generan capital y cohesión social ello tendrá como consecuencia su futura salida de su condición de exclusión.

Sin embargo, los mismos autores han señalado importantes críticas. En primer lugar, la cohesión social no es siempre positiva, barrios fuertemente cohesionados podrían entrar en conflicto con otros contribuyendo a una ciudad fragmentada y dividida. En segundo lugar, la relación entre la supuesta crisis de cohesión social y la crisis de confianza y legitimidad política no es una relación directa, es decir, un barrio fuertemente cohesionado no necesariamente tiene un mayor compromiso democrático o más confianza en las instituciones, asimismo -y muy relevante- fortalecer el capital social de barrios excluidos no implica de ninguna manera superar

\footnotetext{
1 Atkinson et al., 2009.

2 Atkinson, 2000.

3 Dietz, 2002; Atkinson, 2008; Andersson \& Musterd, 2005 y 2010.

4 Kearns \& Parkinson, 2001; Forrest \& Kearns, 2001; Kennett \& Forrest 2006; Forrest, 2008.
} 
la condición de pobreza. Finalmente, el uso, significado y rol del barrio varía enormemente, en consecuencia, estas políticas al considerar el barrio como "el" lugar de la comunidad local, como "el" lugar del capital y cohesión social no consideran esta diversidad.

Considerando que la discusión está lejos de considerarse cerrada, proponemos que este posicionamiento de la escala barrial a finales del siglo XX y principios del XXI está estrechamente conectado con los procesos de reestructuración neoliberal a escala global. Específicamente, planteamos que el barrio cumple un rol estratégico desde el punto de vista ideológico al estar al centro de políticas urbanas que intentan enfrentar las contradicciones propias de la ciudad capitalista, particularmente complejas en el contexto neoliberal.

Para entender estos procesos, el artículo tiene por objetivo bosquejar la figura de la contención en una triple acepción: como consuelo (ante las inevitables condiciones de pobreza y desigualdad), como contenedor (acción del Estado delimitada social y espacialmente) y como control (ante los potenciales conflictos derivados de las condiciones de pobreza y desigualdad).

En función de esta idea central, el artículo se divide en dos partes. En una primera sección se presentan los elementos teóricos que permiten delinear la propuesta de la contención, para en una segunda parte aplicarla en el caso chileno, especialmente representativo pues las políticas de escala barrial han tenido un rol fundamental en las agendas urbanas de los gobiernos post dictatoriales (1990-a la fecha), caracterizados por legitimar, continuar e incluso fortalecer el modelo neoliberal implementado a fuerza de la dictadura cívico militar.

\section{Políticas de escala barrial en el contexto neoliberal}

Proponemos entender el neoliberalismo como un régimen dominante -aunque desigual- caracterizado por un marco institucional que privilegia derechos de propiedad privada, fuertes mercados libres, libertad de comercio y la relegación del rol del Estado a crear y reservar el marco institucional apropiado para el desarrollo de estas prácticas ${ }^{5}$. Resulta útil aquí la propuesta de Jessop ${ }^{6}$, que entiende el neoliberalismo como la estrategia dominante del Régimen Postnacional de Trabajo Schumperiano (RPTS) que surgirá producto de la reestructuración del Estado Nacional de Bienestar Keynesiano predominante en términos gruesos desde el término de la II Guerra Mundial hacia fines del siglo XX.

Jessop propone el Régimen Postnacional de Trabajo Schumperiano como un régimen en tanto se evidencian una serie de mecanismos no estatales para la generación de políticas, tales como la gobernanza (en términos de alianzas público-privadas) y metagobernanza (i.e organismos globales de orquestación económica global); de carácter post nacional ya que se observa una relativización de la importancia de la escala nacional surgiendo otras escalas (más amplias o más acotadas) de relevancia;

5 Brenner et al., 2011; Harvey, 2007.

6 Jessop, 2008. 
de trabajo ya que subordina la política social a la política económica, debilitándose la garantía de derechos sociales; finalmente Schumperiano en tanto promociona la innovación y flexibilidad centrados en el principio de la competitividad.

\section{Neoliberalismo en clave espacial}

En la línea de reafirmar la dimensión espacial en la teoría social crítica es necesario incorporar e integrar la variable espacial en el análisis de estos procesos de reestructuración neoliberal lo cual permitirá comprender de mejor manera el rol fundamental del barrio en las políticas urbanas.

Así, el concepto de espacialidad del Estado propuesto por Neil Brenner ${ }^{7}$ es importante, en tanto permite entender al Estado como una matriz conflictiva y dinámica de interacciones socio espaciales, la cual es activamente producida y transformada por luchas sociopolíticas en sitios institucionales diversos y en un amplio rango de escalas geográficas. En consecuencia, el territorio, el lugar y las escalas son movilizadas por las instituciones estatales para organizar las relaciones sociales. De esta manera, a través de la focalización espacial los Estados intentarán, por ejemplo, mejorar territorialmente ciertos activos de localización, acelerar la circulación del capital, reproducir fuerza de trabajo, enfrentar problemas socioeconómicos de ciertos lugares y mantener la cohesión territorial.

De ahí la relevancia del concepto de selectividad espacial del Estado, entendido como el proceso en que cada formación histórica del Estado y sus políticas privilegian espacios, locaciones y escalas particulares en un territorio nacional dado, marginalizando, negando o excluyendo otras. En ese marco, la gobernanza urbana será el proceso a partir del cual se produce y reproduce la espacialidad del Estado, es decir, la constelación de fuerzas sociales, políticas y económicas que moldean el proceso de desarrollo urbano en el marco del capitalismo moderno. Será a partir de la gobernanza urbana que los Estados intentarán influenciar las geografías de la acumulación de capital y la reproducción social cotidiana de sus territorios.

Esta mirada anglosajona sin duda requiere ser examinada en el contexto latinoamericano, en ese sentido los aportes recientes de investigadores como Rodrigo Hidalgo, Daniel Santana, Voltaire Alvarado ${ }^{8}$ son relevantes, en tanto cuestionan la aplicación de estas categorías de manera acrítica.

En este marco, los autores coinciden en que es necesario considerar que el neoliberalismo en la región fue implantado de manera violenta, a partir de prácticas de imposición y coacción, lejos del carácter más bien horizontal propio de los neoliberalismos light de Estados Unidos e Inglaterra donde efectivamente le antecedió un fuerte régimen keynesiano, siendo necesario además considerar las dinámicas imperialistas que operaron y operan América Latina.

Con el fin de contribuir al debate de la teoría espacial crítica, este grupo de investigadores proponen una serie de conceptos que resultan útiles para una lectura

7 Brenner, 2004.

8 Hidalgo, Alvarado, \& Santana, 2016 y 2017; Hidalgo, Santana, \& Voltaire, 2016. 
desde y para el sur global, a saber, el carácter ideológico del neoliberalismo, su rostro humano y las nociones de expoliación y esquilmo.

Respecto al carácter ideológico del neoliberalismo, los autores proponen entender el neoliberalismo como una ideología social, histórica y espacial que funciona como un mecanismo no sólo para la producción social del espacio -creación de formas materiales y también simbólicas o no materiales que sostienen las relaciones de producción- sino para su misma reproducción, es decir, el mantenimiento y legitimación de las acciones y configuraciones espaciales. En ese marco, e incorporando argumentos de Lefebvre y Zizek, proponen entender ideología como una matriz discursiva -material e inmaterial- que regula una serie de relaciones: visible/invisible, imaginable/inimaginable, realizable/irrealizable y lo deseable/indeseable. En otras palabras, la ideología guía las distintas prácticas sociales señalando qué es lo se puede hacer (y qué no) y qué se puede desear (y qué no), regulación que se hace mediante la legitimación, crítica y proyección de determinados órdenes sociales, temporales y espaciales.

Coherente con ello, el neoliberalismo entonces es un mecanismo ideológico contradictorio y no siempre coherente que opera mediante varios procesos: destrucción (i.e Inglaterra de Thatcher) o absorción de ideologías opuestas (i.e China contemporánea); formación, institucionalización y propagación de valores (i.e libertad económica), reglas (i.e Estado social mínimo) y dogmas (i.e competitividad); finalmente -pero muy relevante- reajustes para responder a sus contradicciones inherentes.

De ese modo, junto a la contradicción central del liberalismo -libertades económicas en detrimento de las sociales y viceversa- los autores identifican para la región un conjunto de nuevas contradicciones tanto sociales, pero también espaciales.

En primer lugar, la restauración o creación de un nuevo poder de las clases capitalistas no ha significado la desaparición del Estado, sino su fortalecimiento o ampliación a partir de su dispersión descentralizada en escalas de gestión local o regional, como mecanismo para individualizar y focalizar las ganancias y socializar las pérdidas y devaluaciones, y finalmente, como ente de coordinación para la apertura y diversificación de la inversiones privadas.

En segundo lugar, la priorización de las libertades económicas genera problemas de demanda efectiva y consumo que se solucionan momentáneamente a través del crédito y la formación de capital ficticio, lo que explica las fuertes y recurrentes crisis financieras.

En tercer lugar, los violentos y continuos procesos de expoliación y esquilmo de las condiciones espaciales para la producción y reproducción de la vida social, a saber la ciudad y la naturaleza, generan la contestación de movimientos sociales.

Es así como el neoliberalismo transita, muchas veces de manera inestable, entre estas contradicciones, intentando regularlas a través del despliegue de procesos de financierización, mercantilizando la naturaleza y, muy importante, lo que los autores denominan "rostro humano", es decir, proporcionando ciertas reivindicaciones 
sociales y espaciales sin alterar los fundamentos ideológicos de mercantilización y privatización.

En esta línea, los autores definen esta supuesta humanización del neoliberalismo como las estrategias orientadas a corregir y ajustar las deficiencias del sistema de acumulación, es decir, el enmascaramiento de las contradicciones inherentes a la ideología neoliberal. De hecho, ante estas contradicciones y el surgimiento de una serie de reivindicaciones sociales, el neoliberalismo se reestructura presentándose con un rostro humano que permite, por una parte, sostener su hegemonía ideológica y, por otra, reproducir relaciones de producción capitalistas. De esta manera, el "rostro humano" del neoliberalismo se entiende como una tendencia al ajuste que el Estado neoliberal aplica sobre las políticas que se dirigen a los pilares básicos de la reproducción social, tales como la salud, la educación y la vivienda, es decir, se reproduce mediante su ampliación y fortalecimiento en pos de solucionar sus contradicciones, esto a través de la producción del espacio.

En último término, la supuesta humanización del neoliberalismo intenta -más o menos exitosamente- disfrazar sus inherentes prácticas de expoliación y esquilmo y así evitar o aminorar los procesos de contestación, para -al mismo tiempo- crear nuevas prácticas que reproducen estas prácticas de explotación. Incorporando los argumentos de la teoría urbana crítica brasileña, los autores definen entonces como expoliación las prácticas que implican la negación al acceso a la ciudad y sus beneficios (i.e centralidad, servicios, localización, habitabilidad) a los habitantes más pobres en pos de las clases y usos más rentables. Eso tiene como consecuencia el esquilmo, entendido como un proceso de debilitamiento y agotamiento de los valores de uso que brindan determinados bienes comunes, en el caso de la ciudad, la centralidad, heterogeneidad y la simultaneidad son socavadas a través de las prácticas de expoliación urbana.

\section{Nadando en aguas revueltas o el equilibrio entre Escila y Caribdis: aportes desde la Economía Política Cultural}

El enfoque de la Economía Política Cultural (EPC) representa una propuesta teórica relevante para los debates latinoamericanos, especialmente en relación a los temas urbanos pues permite, entre otras cosas, superar dialécticamente la oposición rígida entre los planteamientos que enfatizan lo local y aquellos vistos como universales/ globales 9 . Además, constituye un enfoque teórico con ambiciones de proveer análisis generalizadores, lo que consideramos podría contribuir a complementar la mirada espacial del neoliberalismo.

De hecho, la EPC adhiere a la idea de tomarse en serio el giro cultural ${ }^{10}$ asociado al giro espacial Soja ${ }^{11}$, sumándose dos esfuerzos conjuntos: proponer herramientas teóricas para enfrentar temáticas donde las categorías económicas clásicas de la

9 Valenzuela, 2014.

10 Jessop, 2004 y 2010; Sum \& Jessop, 2013.

11 Jessop en Warf \& Arias, 2008. 
Economía Política eran demasiado universalistas, simples y totalizadoras ${ }^{12}$ y re-empoderar y re-balancear la dimensión espacial-geográfica sin negar los innegables aportes de la perspectiva social histórica. En otras palabras, incorporar la cultura y el espacio en el análisis, como dimensiones igualmente relevantes ante la política, la economía, la historia y la teoría social, pensando estas dimensiones como procesos co-constituidos.

En este marco propone entender la cultura como semiosis, es decir, como procesos de producción de sentido y significado, asociado al concepto de discurso ${ }^{13}$. Esto significa incorporar la dimensión semiótica (discursos) en integración con los elementos políticos y económicos (estructura), reconociendo el rol constitutivo tanto de los discursos como de los elementos extra discursivos y su impacto conjunto en las capacidades para la acción y la transformación social. El desafío investigativo es entonces navegar con pericia entre Escila y Caribdis: entender y explicar procesos sociales sin estrellarse en la inmutabilidad y rigidez de la estructura (Escila), pero tampoco hundirse en las aguas profundas del discurso (Caribdis).

Esto no es ni mucho menos un ejercicio neutral ${ }^{14}$ : aunque este enfoque general puede adaptarse a contextos pre capitalistas, tiene su base en la tradición marxista y por ende implica un especial interés en examinar las contradicciones, crisis y dilemas del capitalismo, sus condiciones de existencia y su potencial impacto en las relaciones sociales. En esta línea, explorar el orden capitalista del mundo implica identificar las prácticas sociales y los mecanismos que gobiernan la dinámica de acumulación y la hegemonía del capital. En estos términos, la EPC implica una forma de intervención política que no sólo pretende revelar los intereses ideales y materiales detrás de específicas ideologías y sistemas de significación, sino que también explorar los procesos mediante los cuales ciertos sistemas de significación e ideologías dominan y/o hegemonizan a otros.

En este marco general desarrolla una serie de conceptos que contribuyen a entender el rol de las políticas de escala barrial en el Chile contemporáneo.

En primera instancia, la idea del régimen de regulación ${ }^{15}$. Incorporando importantes elementos de la denominada teoría de la regulación, la EPC entiende que la acumulación continua de capital es inherentemente improbable, no natural y por ende problemática, por lo cual una pregunta central es ¿cómo el capitalismo puede sobrevivir si la relación de capital es en sí misma generada por antagonismos, crisis y contradicciones? La respuesta es la distinción entre régimen de acumulación y el régimen de regulación: la expansión y reproducción del orden macroeconómico (régimen de acumulación) es un proceso contradictorio, por lo que requiere de un conjunto de normas, instituciones y redes sociales que garanticen, al menos por un momento y lugar, el orden social (régimen de regulación).

12 Ribera-Fumaz, 2009.

13 Jessop en Goede, 2006; Jessop, 2010; Sum \& Jessop, 2013.

14 Jessop, 2004; Jessop en Goede, 2006.

15 Jessop \& Sum, 2006. 
En segunda instancia el concepto de Estado y políticas públicas ${ }^{16}$. Si el régimen de acumulación es contradictorio, el régimen de regulación tampoco escapa de los antagonismos y divergencias, de esta manera, el Estado tiene un rol fundamental entendido como el conjunto de normas estructurales, instituciones y organizaciones que intentan asegurar las condiciones para la acumulación y manejar el equilibrio inestable de diversas fuerzas sociales. Para ello cuenta con un conjunto de instrumentos, entre ellos, las políticas públicas, que tienen como objetivo central compensar los fallos del mercado y asegurar las condiciones básicas para la reproducción del capital. En ese marco, las políticas sociales -y por derivación las urbanas y habitacionales- refieren a garantizar las condiciones para la siempre problemática reproducción de la fuerza de trabajo y hacer frente a las repercusiones sociales y políticas derivadas de los dilemas y contradicciones capitalistas.

En tercera instancia, el concepto de hegemonía e ideología ${ }^{17}$. Para lograr cierta estabilidad se requiere la acción de un Estado que tenga fuerza suficiente para hacer cumplir obligaciones (coerción), pero que estas obligaciones estén sustentadas en un bien común (consenso), es decir, que se logre instaurar como común una idea particular acerca del interés público, de la buena sociedad, del bienestar o de cualquier otro principio. Incorporando los argumentos de Gramsci, la EPC entiende la hegemonía como el ejercicio de un liderazgo político, intelectual y moral que establece una particular visión de mundo, expectativas y valores como los únicos posibles y que se ajusta a los requisitos de la reproducción capitalista en un periodo determinado. En este marco, la ideología son aquellos sentidos y significados vinculados a ciertos intereses ideales como materiales, es decir, las visiones de mundo asociadas a determinados intereses que lucharán por constituirse como hegemónicos.

En cuarto lugar las tecnologías gubernamentales ${ }^{18}$. El régimen de regulación tiene como un actor central el Estado que tiene el poder para establecer obligaciones definidas por cierta visión del bien público hegemónica, pero una pregunta queda pendiente ¿cómo se ejerce este poder en la sociedad contemporánea? La EPC retoma en este punto los argumentos de Foucault y específicamente el concepto de tecnologías gubernamentales como las prácticas sociales diversas mediadas por instrumentos específicos de clasificación, registro, cálculo, etc., que disciplinan la acción social, proveen de puntos de referencia en la producción de significaciones y coordinan acciones entre personas, organizaciones, redes y ordenes institucionales. Esto significa que las políticas, sus técnicas de decisión política y los instrumentos para diseñarlas y evaluarlas son tecnologías importantes porque contribuyen a relevar ciertos discursos políticos por sobre otros, además de tener efectos sociales concretos y materiales. En ese sentido, las tecnologías gubernamentales permiten la explotación de los cuerpos y los tiempos en función de la ganancia y son estratégica-

16 Jessop \& Sum, 2006; Jessop, 2008.

17 Jessop, 2008; Gramsci, 1988 Gramsci, 1980.

18 Sum \& Jessop, 2013; Jessop, 2007; Sum y Jessop en Goede, 2006; Foucault, 1996, 1999, 2000 y

2012; Jessop, 2010. 
mente y selectivamente desplegadas para producir hegemonía y consolidar estados de dominación.

Finalmente el concepto de semiosis y discurso ${ }^{19}$. Las tecnologías gubernamentales están asociadas a ciertas significaciones y sentidos que son promovidos por fuerzas sociales dominantes, aparatos e instituciones. En esa línea, la semiosis refiere justamente a la producción social de sentidos y significados, es decir, como se aprehende e interpreta la realidad y en función de ello como se actúa. Este no es un proceso neutral, pues la semiosis define qué es lo que puede ser dicho o nombrado (y lo que queda fuera) y ello está relacionado con diferentes tipos de asimetrías en las relaciones sociales. De esta manera algunos sentidos y significaciones son más hegemónicos o al menos dominantes y por tanto tienen mayor peso en la construcción de las formas de pensar y existir, así, en las formaciones sociales capitalistas estos sentidos y significaciones permiten dar coherencia a los patrones de explotación y dominación.

Es en este marco que la EPC se interesa especialmente en desnaturalizar los discursos, entendidos como los conjuntos particulares de prácticas semióticas, es decir, la producción de sentidos y significados qué construyen y consolidan, al menos temporalmente, sentidos y significaciones del mundo social que se establecen como dados. En consecuencia, podemos afirmar que la semiosis tiene una dimensión ideológica, en tanto los sistemas de sentidos y significaciones -aunque se presenten como coherentes- tienen contradicciones e inconsistencias, pues detrás de algunos de ellos hay ciertos intereses ideales y materiales que buscan establecer cierta visión de mundo como la dominante y/o hegemónica: la ideología configura la experiencia de vida privilegiando algunos puntos de vista por sobre otros y puede promoverse intencionalmente para llegar a constituirse como sentido común.

De ahí que la EPC propone revelar estas contradicciones e inconsistencias, mostrar los intereses materiales e ideales que están detrás de ciertos marcos de sentido y significado y contribuir a la repolitización y rearticulación de los discursos y prácticas naturalizadas, objetivo al que intentamos contribuir en este artículo.

\section{Esbozando la figura de la contención}

Considerando los anteriores argumentos es posible proponer algunos elementos que configuran la idea de la contención para entender el protagonismo del barrio en las políticas urbanas neoliberales.

En tanto espacialidad, las políticas de escala barrial implican la selección de una escala específica por parte del Estado para intentar regular relaciones sociales y garantizar la acumulación de capital. Específicamente, proponemos que el barrio tiene un rol fundamental como escala que se moviliza y privilegia para enfrentar los efectos desestabilizadores de la reestructuración neoliberal, es decir, en tanto política pública constituye parte relevante del régimen de regulación que contribuye a garantizar el orden social.

19 Sum \& Jessop, 2013; Jessop, 2008. 
En esta línea, las políticas de escala barrial se configurarían como tecnologías gubernamentales que permiten el disciplinamiento de la población marginada o desposeída de/por los procesos de neoliberalización, de ahí que no es casualidad que en términos globales se observe a partir de los noventa la proliferación de programas de regeneración urbana y bienestar social a partir de focalizaciones espaciales centradas en esta escala ${ }^{20}$.

Específicamente, estas políticas cumplirían un rol de disciplinamiento, por ejemplo a partir de asignación de responsabilidades. Así, un punto en común a las políticas de escala barrial es el traspaso de recursos, responsabilidades y riesgos al ámbito local ("hacia abajo") y a las agencias extra estatales ("hacia los lados"), mientras que los marcos generales de decisión están situados en estructuras tecnocráticas y convenciones lideradas por agencias transnacionales y marcos mega reguladores ("hacia arriba”), evidenciando dos ironías: representan la profundización, pero al mismo tiempo la fragilidad del proyecto neoliberal y, por otro lado, implican la transferencia de riesgos y responsabilidades a agencias, actores y jurisdicciones locales que son al mismo tiempo impotentes en términos de poder de decisión

Estas políticas de escala barrial tienen también una dimensión semiótica relevante, fuertemente vinculadas a los discursos que levantan las banderas de lo local y lo comunitario, pero en el sentido de profundizar los procesos de neoliberalización. Así, encarnarían la llamada "trampa comunitaria"21, pues invocarían el espíritu de la comunidad como antídoto a cualquier intento de desorden social, lucha de clases y violencia revolucionaria. Es decir, el concepto de barrio centro de estas políticas promueve cierto contenido ideológico asociado a la idea de comunidad, pero que opera como una barrera al cambio social.

En este marco, es preciso destacar que el levantamiento de las banderas de la comunidad/comunitario/local no implican forzosamente una oposición a los procesos de neoliberalización, por el contrario, como indica Gough ${ }^{22}$ los procesos de cooperación y coordinación no regulada por el mercado (socialización) no desaparecen en esta fase de reestructuración neoliberal, más bien se fortalecen: lo que tiende a debilitarse son aquellas formas de socialización amenazantes de resistencia, revuelta o propuesta a la reestructuración neoliberal. En este contexto, la creación de pobreza por parte del régimen neoliberal no es una demanda que interesa sólo a los pobres, sino que es problemático para el capital en tanto aumentan los costos sociales, se agudizan problemas de delincuencia, violencia etc. y se alteran los procesos de reproducción de fuerza de trabajo. Así, las políticas de escala barrial en un llamado a lo local y lo comunitario ayudarían a enfrentar esta contradicción, pero en función de la continuidad de la reestructuración neoliberal y distrayendo del objetivo de desafiar al poder que justamente crea la pobreza: en último término controlan la posibilidad de acciones comunitarias radicales, fragmentando social y

20 Peck \& Tickell, 2002; Brenner et al., 2009.

21 Harvey, 1997.

22 Gough, 2002. 
culturalmente a la clase trabajadora y la población pobre e instalan auto disciplina y dependencia en sectores potencialmente radicales.

En la línea de la propuesta integradora del enfoque de la Economía Política Cultural e incorporando la mirada latinoamericana, proponemos explorar las políticas de escala barrial como una forma de regulación, pero también como una matriz ideológica. En función de ello, se propone la figura de la contención en el sentido de que las políticas de escala barrial expresarían la supuesta humanización del neoliberalismo, es decir, uno de sus objetivos es aminorar los efectos contestatarios y conflictivos de las prácticas de expoliación y esquilmo, permitiendo al mismo tiempo su reproducción. Retomando los argumentos de Foucault, el supuesto rostro humano del neoliberalismo evidencia la importancia fundamental del control social como parte de los dispositivos de estabilidad del modelo, las políticas de escala barrial podríamos entenderlas entonces como una manera de ganar consenso político y al mismo tiempo atenuar el conflicto social potencial que generan las contradicciones del modelo de desarrollo urbano.

Es en este sentido que Socarras ${ }^{23}$ releva el carácter correctivo y resiliente del neoliberalismo, demostrando su enorme capacidad de renovación y recomposición. Siguiendo al autor, las críticas al modelo vigente y los cambios - mas no transformaciones- a nivel de políticas públicas mantienen intacto el paradigma y la estrategia de desarrollo. De esta manera, las políticas de escala barrial implican la introducción de medidas en pos de mejorar las condiciones de vida de los habitantes expulsados de la ciudad, pero no alteran el proyecto político hegemónico de desarrollo urbano, sino que más bien lo reforzaría.

\section{Reestructuración neoliberal "a la chilena" y las políticas de escala barrial}

Hace aproximadamente tres décadas atrás (1988) se votó en las urnas la salida del dictador Augusto Pinochet, sin embargo pocas muestras hay de dar por superado dicho periodo. Por el contrario, se observa en la actualidad un momento de inflexión, malestar y procesos de politización de la sociedad chilena ${ }^{24}$, que mira con atención las bases en la cuales se ha construido el país desde la dictadura cívico-militar, las promesas de la democracia, la oferta de cambio de la centro derecha y ahora la posibilidad de construir ( o no) nuevas bases para el Chile de las próximas décadas.

En este marco surge una paradoja inquietante: ante el ciclo de movilización social crítico a aspectos claves del modelo neoliberal ¿por qué el aparente conformismo con los temas urbanos? Esto considerando la enorme importancia del llamado "movimiento de pobladores" de fines de los sesenta y durante la dictadura ${ }^{25}$, así como las temibles cifras de desigualdad y pobreza urbana en el país ${ }^{26}$.

23 Puello-Socarrás, 2015.

24 Programa de las Naciones Unidas para el Desarrollo, 2012 y 2015.

25 Castells, 1973; Castillo, 2014; Chateau, 1987; Garcés, 2002, 2011.

26 OECD, 2013, p. 15; Arriagada, 2014; Jirón \& Mansilla, 2014; Ruiz-Tagle, 2014; Ruiz-Tagle \& López, 2014; Sabatini et al., 2001; French-Davis, et al., 2014; López, 2014. 
En este artículo proponemos que la razón que explica este aparente conformismo e invisibilidad frente a la estructuración neoliberal en la dimensión urbana es justamente el despliegue exitoso de políticas en este campo, iniciadas en dictadura, pero extensivas a los gobiernos post dictatoriales. Estas políticas han facilitado estructuralmente (Escila) la implementación de procesos neo liberalizadores, básicamente, la mercantilización casi total del suelo, la vivienda y el desarrollo urbano en general, pero también han significado la promoción de determinados discursos (Caribdis) que han contribuido a naturalizar estos procesos y sostener la hegemonía del modelo neoliberal. Asimismo, contemplan como eje primordial la desmovilización política ${ }^{27}$, especialmente centradas en impedir que los sectores que en dictadura habían apoyado reivindicaciones fundamentalmente en torno a la vivienda afectaran el denominado retorno a la democracia.

De ahí el problema y apuesta de distinguir entre la dictadura y los gobiernos post dictatoriales chilenos de 1990 a la fecha, periodo marcado por cuatro gobiernos de centro izquierda (Concertación de partidos por la democracia o simplemente Concertación), un cambio de signo político a la centro derecha y posteriormente la vuelta de la centro izquierda en un formato nuevo que incorpora al Partido Comunista como parte de la coalición (Nueva Mayoría): Patricio Aylwin (1990-1994), Eduardo Frei (1994-2000), Ricardo Lagos (2000-2006) y Michelle Bachelet (20062010 ) por la Concertación; Sebastián Piñera (2010-2014) como líder de la centro derecha; finalmente, la vuelta de Michelle Bachelet (2014-2018).

En este artículo planteamos que existe una continuidad entre la dictadura y los gobiernos posteriores, continuidad en términos del mantenimiento de los elementos básicos neoliberales y matices en tanto se plantea una preocupación por los sectores más pobres del país lo que en la actualidad se traduce en términos de desigualdad. Matices que en tanto no tocan el núcleo de los principios neoliberales, aportan a su fortalecimiento y legitimación. Desde el punto de vista urbano esto es claro, pues la faceta espacial de las transformaciones promovidas por el régimen cívico militar han sido sostenidas por los gobiernos siguientes, con independencia del signo político ${ }^{28}$, de ahí que coincidamos plenamente con Hidalgo, Santa y Alvarado en denotar el periodo como post dictadura y no como retorno a la democracia, en tanto existe continuidad en términos de la estructura económica como ideológica dictatorial.

Esto en el marco de lo que llamamos la cláusula de divorcio firmada entre los líderes militares y civiles de la dictadura y la elite política pro democrática ${ }^{29}$ : cláusula que establece que entre el cuestionamiento a los principios reguladores de la sociedad chilena y la estabilidad del sistema democrático, el deber y responsabilidad política es privilegiar este último. De modo que la estabilidad está siempre condicionada al mantenimiento de los principios reguladores que definen el sistema demo-

27 De la Maza, 2005 y Castillo, 2013.

28 Hidalgo, Santana, et al., 2016.

29 De la Maza, 2004. 
crático "recuperado". Así, la transición chilena habría sido más o menos exitosa en términos de democratización política (participación política libre), pero altamente limitada en términos de democratización social (igualdad social y económica), como resultado, el proceso de transición chileno da cuenta de una democracia restringida, tutelada y de baja intensidad ${ }^{30}$.

En consecuencia, las políticas públicas post dictatoriales se caracterizan por un doble objetivo, por una parte asegurar la estabilidad del sistema político para continuar con las principales directrices del modelo neoliberal y por otra diferenciarse del pasado en términos de desarrollar políticas públicas sociales centradas en la población más pobre del país ${ }^{31}$. Todo ello con una condición inapelable: el respeto irrestricto a la cláusula de divorcio de la transición chilena y el sacrificio que esta conlleva. Es en ese marco que las políticas de escala barrial tendrán un rol preponderante, como contención de las consecuencias de los procesos de neoliberalización en la dimensión urbana.

\section{Chile en el concierto latinoamericano.}

En esta línea, las dictaduras latinoamericanas y específicamente la chilena constituyeron el golpe de timón básico que permitió un nuevo orden social ${ }^{32}$ basado en la retirada del Estado del Estado Desarrollista o lo que hemos llamado Estado Nacional de Bienestar Keynesiano y la re articulación neoliberal. Estos procesos de neoliberalización se desarrollan en dos etapas fundamentales ${ }^{33}$ :

Primeramente, en la década de los ochenta, una etapa de liberalización económica que en síntesis buscaba la reducción del tamaño del Estado y la redefinición de las relaciones entre Estado, mercado y sociedad civil en términos del modelo neoliberal.

Posteriormente, en los años 90, se observa que las promesas de la liberalización no se cumplían del todo y que la pobreza seguía siendo un enorme problema, de ahí la necesidad de una vuelta del Estado, re inventado. Esta resurrección del Estado será en términos neoliberales, en tanto los "efectos colaterales" del modelo -evidenciados en la población marginada- ponían en peligro la estabilidad del proceso, por tanto la integración social se definirá como tarea prioritaria. Es en dicho contexto que las políticas de escala barrial tendrán un rol fundamental, pues no solo están orientadas a la compensación por las disfuncionalidades de una economía de mercado, sino que se constituyen como pilares centrales y vitales de reorganización social ${ }^{34}$

Esta vuelta al Estado se refleja entonces en políticas públicas con una nueva terminología asociada a conceptos como capital social, cohesión social, empoderamiento, participación etc. ${ }^{35}$, asociadas al repliegue de políticas públicas de carácter

30 Garretón, 2000a; Grez, 2011.

31 Castillo, 2004.

32 Garretón, 2012.

33 Haggard \& Kaufman, 1995 en Santiso, 2001.

34 Lechner, 2003.

35 Molyneux, 2000. 
universal y el despliegue de políticas públicas de carácter focalizado, con énfasis en la responsabilidad y participación de la ciudadanía, la comunidad y lo local. Así, esta focalización implica la retirada de los derechos sociales universales; la transformación de los derechos en beneficios; el carácter individualizado de estos; y, la consolidación de un sistema compensatorio donde los pobres tienen estos beneficios mientras que esperan su "entrada" al mercado ${ }^{36}$.

En Chile dicho proceso se evidencia en la fundación dictatorial del Estado subsidiario $^{37}$, que en términos económicos implica liberalización, apertura externa y privatización y en el campo social la reducción del gasto social, transferencia de funciones estatales al sector privado, eliminación de los programas y políticas de garantía universal, introducción de mecanismos de mercado en la asignación de recursos públicos (subsidio a la demanda) y focalización de éstos en los sectores más pobres, entre otros aspectos.

\section{Neoliberalización en clave urbana}

Será entonces en marco general de este Estado resucitado (o zombie, según como se le mire) donde se contextualizan las políticas urbanas de escala barrial, de modo que su surgimiento está estrechamente vinculado con el despliegue de políticas sociales en el marco del retorno del Estado en términos neoliberales. Específicamente en el campo urbano, los programas de mejoramiento barrial latinoamericanos serán una de las acciones más relevantes en términos de focalización espacial y social, con una importancia estratégica en la reducción del conflicto que acarrea la pobreza urbana asegurando estabilidad y gobernabilidad, aspectos claves para la competitividad de las ciudades en la lógica global ${ }^{38}$, donde se pueden distinguir tres etapas de implementación:

Un primer momento caracterizado por la orientación a solucionar el problema de los asentamientos informales ${ }^{39}$, es decir, proveer infraestructura y servicios urbanos básicos así como la regularización de la tenencia de la tierra de conjuntos de viviendas irregulares. En un segundo momento se integra el componente participativo y desarrollo comunitario para constituirse como programas integrales en el sentido de incluir infraestructura urbana (no sólo vivienda) y acciones relativas a atención a grupos vulnerables, generación de ingresos, educación, salud y otras actividades sociales.

Un tercer momento sería la incorporación de los problemas de la ciudad for$\mathrm{mal}^{40}$. Si anteriormente el énfasis estaba dado en los asentamientos informales, para el fin de los años 2000 se distingue un proceso de deterioro de barrios originalmente regulares los cuales presentaban problemas similares a los de los irregulares, es decir, problemas de deterioro físico y social de conjuntos de viviendas construidos por

36 Alonso, 2000; Adelantado \& Scherer, 2008.

37 Garretón, 2000b y 2009.

38 Fernández, 2001.

39 En Chile llamados también "campamentos"

40 Rojas, 2009. 
el Estado para familias de bajos ingresos, convirtiéndose prácticamente en guetos. Esto se conceptualiza como problemas de "segunda generación", es decir, no sólo deterioro físico, falta de vivienda e irregularidad, sino que agudos problemas en el ámbito de las relaciones sociales en los barrios de viviendas construidas por el Estado, los cuales comenzaban a evidenciar problemas homólogos a los de los asentamientos irregulares: bajos niveles de servicios de la infraestructura, mala calidad de las viviendas, deterioro de las relaciones comunitarias y alta incidencia de problemas de seguridad y convivencia ciudadana.

En Chile los procesos de neoliberalización fueron incrustados a sangre y metralla y el ámbito urbano no sería la excepción ${ }^{41}$. Principalmente se asegura la privatización y mercantilización total del suelo, la vivienda y el desarrollo urbano a partir de la ley que establece que el suelo urbano no es un recurso escaso, sino ilimitado, y que su uso y rentabilidad debía ser definido por la mayor rentabilidad y la inversión privada $^{42}$.

El golpe de gracia sería la política habitacional, donde se repliega la política de derecho a la vivienda y se despliegan los subsidios como beneficio individual para acceder a la vivienda, subsidiando a la demanda, es decir, el individuo es el responsable directo de alcanzar su solución habitacional en término de la lógica de mercado. En esta línea, el Estado entregará a los privados todo el ciclo de la política habitacional, desde la vivienda social a la general, sometido a la lógica de la ganancia ${ }^{43}$.

Los gobiernos post dictatoriales han mantenido los principios que guían el paradigma ${ }^{44} \mathrm{y}$, como hemos dicho, aunque las cifras acusan agudos niveles de desigualdad socio espacial, poco se ha hecho para modificar las bases que sustentan el modelo, de manera que la mercantilización del suelo, la vivienda y el desarrollo urbano es clara, lo que se suma a un marco de planificación que es contradictorio y engorroso. De este modo, no existe una política urbana chilena consistente, son más bien iniciativas inconexas que tienen como foco las políticas de vivienda social - de nuevo la focalización en la pobreza- que por su carácter subsidiario y entregado a los agentes privados están marcadas por condiciones de constructibilidad y localización sumamente restrictiva.

Esto implica que si bien a partir del año 2006 se identifica un giro desde la cantidad a la calidad de las viviendas, donde la política habitacional se contextualiza en el desarrollo urbano y el foco en la escala barrial representa el interés en la calidad de vida urbana de los habitantes de conjuntos de vivienda social, la realidad es que al no enfrentar el tema de la privatización del proceso urbano, la política habitacional sigue construyendo allí donde el suelo es más barato, y por tanto acrecentando las brechas y desigualdades urbanas ${ }^{45}$, la ironía en ello no es precisamente alegre: mientras se "recupera" un barrio se genera otro.

41 Ministerio de Vivienda y Urbanismo, 2004.

42 Gurovich en López et al., 2014.

43 Hidalgo, 1999; Rodríguez \& Rodríguez, 2013; Larenas en López et al., 2014

44 Gurovich, 2014; Inzulza, 2014; Arriagada, 2014.

45 Larenas, 2014. 


\section{Trayectoria de las políticas de escala barrial en el Chile post dictadura}

El barrio como escala de planificación no está formalizado en los instrumentos legales que regulan la planificación urbana chilena, siendo las juntas de vecinos la entidad pertinente al ámbito local. De esta manera, el barrio como protagonista de políticas urbanas tiene la particularidad de haberse promovido -sin estatus legal- como escala de intervención contingente y relevante a partir de los gobiernos post dictatoriales a partir de programas de mejoramiento barrial liderados principalmente por el Ministerio de Vivienda y Urbanismo ${ }^{46}$ (cuadro 1).

De esta manera, el barrio aparece de manera definitiva y explícita en los marcos de acción del MINVU con el programa Chile Barrio (1998-2006). Este programa representa la continuidad del programa de saneamiento de poblaciones promovido por el Banco Interamericano de Desarrollo ${ }^{47}$, pero es el primer programa financiado exclusivamente con fondos nacionales con foco en la radicación de asentamientos informales, con énfasis en la integralidad y la dimensión social propia de la segunda etapa de implementación del enfoque de políticas de escala barrial.

El Programa Chile Barrio surge el año 1997 y se enmarca en el Programa de Superación de la Pobreza que se implementa en el segundo gobierno de la Concertación, que reconocía que había un sector de la población que no parecía poder superar su condición a través del crecimiento económico ni de las políticas sociales tradicionales.

Así, Chile Barrio incorpora dos lineamentos políticos fundamentales: primero, la focalización territorial como un elemento nuevo para aumentar la eficiencia y eficacia de la acción pública en materia de superación de la pobreza y, segundo, la consideración del actor privado -en reemplazo del Estado- como protagonista operativo de estas acciones ${ }^{48}$

Ambos principios se plasmarían en el Programa Chile Barrio: en coherencia con la política urbano-territorial implementada en la época, la provisión de vivienda definitiva era conducida y realizada por capitales privados de acuerdo a la lógica del mercado y el programa adhiere al principio de focalización de las políticas sociales

46 Existen otras iniciativas que consideran el barrio como escala de intervención, tales como el programa "Barrio en Paz" del Ministerio del Interior vinculado a temas de seguridad o el programa de Fortalecimiento de Barrios Comerciales del Ministerio de Economía, Fomento y Turismo con objetivos de innovación económica y emprendimiento. En este artículo interesan los programas de escala barrial liderados por el Ministerio de Vivienda y Urbanismo en tanto principal entidad gubernamental encargada del diseño e implementación de políticas públicas urbanas.

47 El Programa de Mejoramiento de Barrios (1983-1994) iniciado en dictadura y con financiamiento directo del Banco Interamericano de Desarrollo es el primer programa iniciado en América Latina con focalización espacial y social para otorgar servicios urbanos mínimos y tenencia formal de propiedad a la población que vivía en asentamientos informales (Sepúlveda, 1994). Una vez finalizado el financiamiento BID, parte de los objetivos se continuaron en el Programa de Mejoramiento de Barrios del Ministerio del Interior, sin embargo éste programa no constituye una proporción relevante del presupuesto nacional (Dirección de presupuestos. Gobierno de Chile, 2012), siendo el Programa Chile Barrio la evolución de esta iniciativa (Rojas, 2009).

48 Ministerio de Vivienda y Urbanismo, 2010 
incorporando la dimensión territorial. De manera que el principal instrumento del programa Chile Barrio fue el "Catastro de campamentos y asentamientos irregula-

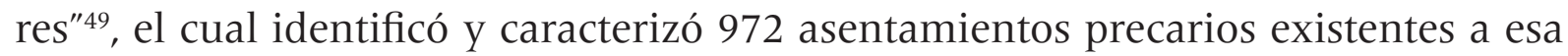
fecha.

En este marco, el Programa Chile Barrio define como objetivo central "contribuir, a través de una acción intersectorial de carácter integral, a la superación de la pobreza de los habitantes de asentamientos precarios identificados en el Catastro Nacional de Asentamientos Precarios, poniendo a su disposición alternativas para un mejoramiento sustancial de su situación residencial, de la calidad de su hábitat y de sus oportunidades de inserción social y laboral"50. Para ello define un modelo operativo articulado en tres ejes ${ }^{51}$ : el proyecto habitacional (solución concreta de vivienda y mejoramiento barrial a través de la provisión de subsidios existentes; el servicio para el desarrollo del barrio ( apoyo técnico en terreno para promover y facilitar la participación de la población del asentamiento en las decisiones); finalmente, el programa un barrio para mi familia (intervención realizada una vez los conjuntos de vivienda social eran entregados con el fin de dejar instaladas capacidades para el desarrollo de los nuevos barrios).

Sin embargo, a partir del año 2001, coincidente con el tercer gobierno de la Concertación encabezado por Ricardo Lagos, se observan una serie de críticas y modificaciones al programa.

Principalmente, el programa consideraba como cumplimiento de la meta los asentamientos egresados de acuerdo al catastro de 1997, pero para el año 2001 fue evidente que el problema era mucho más complejo, pues a medida que egresaban campamentos, se formaban otros nuevos. En consideración de ello, o más bien ignorando este último punto, se decide acelerar el cumplimiento de sus objetivos a través de una estrategia de intervención total de los asentamientos considerados en el catastro.

Además, el programa estuvo sometido a varias tensiones, internamente se criticaba que podría fomentar -en vez de aminorar- las tomas de terreno ya que ofrecía solución rápida y priorizada a asentamientos informales; también, que generaba una competencia y discriminación entre aquellos que postulaban a los subsidios habitaciones sin vivir en los asentamientos catastrados y aquellos que no cumplían los requisitos de los subsidios, pero obtenían beneficios por el hecho de residir en campamentos. Desde el punto de vista más académico varias eran las inquietudes ${ }^{52}$ : las operaciones del programa significaban fomentar lógicas clientelares y favores políticos; las soluciones habitacionales reforzaban la lógica segregadora al localizarse en los terrenos más baratos; mientras el programa se ejecutaba los campamentos continuaban surgiendo; el programa afectaba redes de solidaridad y tejido social que se habían construido durante años al implementar una lógica de solución in-

49 Instituto de la Vivienda. Facultad de Arquitectura y Urbanismo. Universidad de Chile, 1997

50 Dirección de presupuestos. Gobierno de Chile, 2007

51 Ministerio de Vivienda y Urbanismo, 2010.

52 Margarit, 2003; Rodríguez \& Sugranyes, 2004; Saborido, 2005. 
dividual de vivienda; finalmente, las nuevas viviendas muchas veces eran de peor calidad que las construidas por los mismos habitantes.

Es en este marco que asume Michelle Bachelet el año 2006, donde se daría a conocer una evaluación del programa donde se recomienda la no continuidad del Chile Barrio. Además, para este momento el tema predominante serían los habitantes de los barrios de vivienda social formal (los "con techo") por lo que el nuevo programa Quiero Mi Barrio adquiere especial protagonismo y lideraría una nueva etapa en las políticas urbanas habitacionales.

En este sentido, aunque en cuanto al objetivo específico de intervención (asentamientos informales) no habría una continuidad estricta entre ambas iniciativas ${ }^{53}$, en cuanto a relevancia y contenido si es posible afirmar una trayectoria común, pues tal como lo señala Morris ${ }^{54}$ el programa Quiero Mi Barrio es sucesor del Chile Barrio en términos de constituirse como programa ancla de la política urbano territorial, incorporando importantes elementos del modelo de intervención e incluso integrando a muchos de los antiguos profesionales.

El Programa Quiero Mi Barrio (2007-2010) tiene como fecha de nacimiento el 27 de diciembre del año 2005, cuando Michelle Bachelet a pocos días de enfrentarse a la segunda vuelta electoral anuncia la medida número 30 de su futuro gobierno: "un amplio programa de intervención urbana, identificando 200 barrios a mejorar en todo Chile" 55

Esta medida sería asumida legalmente a través del Decreto Supremo ${ }^{\circ} 14$ del Ministerio de Vivienda y Urbanismo denominado como Programa de Recuperación de Barrios, donde se define el reglamento y objetivos de la iniciativa. Asimismo, el manual de procedimientos, contenido en la Resolución Exenta $N^{\circ} 4119$ del Ministerio de Vivienda y Urbanismo. Ambos instrumentos son los que regulan el programa desde el 2007 a la fecha, de manera que el programa se extendió desde el primer gobierno de Bachelet (Quiero Mi Barrio), pasando por el gobierno de Piñera (Programa de Recuperación de Barrios) y retomándose en el segundo gobierno de Bachelet (Quiero Mi Barrio II), con distintas nomenclaturas, pero los mismos principios articuladores.

El objetivo central del programa es el mejoramiento de la calidad de vida de los habitantes de barrios que presentan problemas de deterioro urbano, segregación y vulnerabilidad social ${ }^{56}$. El deterioro urbano se refiere a situaciones tales como segre-

53 El problema de los campamentos pasarían a un segundo plano en este periodo, a partir de la preocupación por la calidad más que la cantidad de soluciones habitacionales. Además, el año 1997 ya se había formalizado la iniciativa privada y dependiente de la Iglesia Católica "Un Techo para Chile", la cual adquiere enorme y creciente legitimidad como modelo de intervención en campamentos. En el Ministerio de Vivienda y Urbanismo, los campamentos fueron abordados a partir del año 2006 en la denominada Línea de Atención de Campamentos y posteriormente (2010) se creó el programa de Campamentos.

54 Morris, 2012.

55 Ministerio de Vivienda y Urbanismo, 2008a, p. 3.

56 Si bien el programa integró nuevas tipologías de barrio, a saber, los barrios de interés patrimonial (2011) y los barrios de interés regional (2012), en magnitud y objetivos el foco sigue siendo los barrios identificados como vulnerables. 
gación urbana, déficit o deterioro del espacio público, infraestructura y/o de equipamiento colectivo, imagen ambiental degradada y/o con problemas de conectividad y/o accesibilidad. La vulnerabilidad social en tanto, se refiere a situaciones donde los habitantes tienen un débil sentido de pertenencia, estigmatización negativa, deterioro en las relaciones sociales, inseguridad ciudadana, concentración de problemas en ámbitos de educación, recreación y cultura, emprendimiento y población vulnerable.

Para ello se definen tres etapas de intervención:

Etapa I Elaboración del contrato de Barrio: Difusión del programa y conformación de equipos ejecutores; realización de un diagnóstico participativo del barrio; en base a ello la formulación del Proyecto Integral de Recuperación del Barrio, el cual se concretiza en la definición de las obras físicas a realizar (Plan de gestión de obras) y las acciones sociales a implementar (Plan de gestión social). Además, el programa contempla la constitución de un Consejo Vecinal de Desarrollo (CVD) conformado por vecinos y vecinas del barrio principal interlocutor y entidad representante del barrio, este consejo es el que suscribe el contrato de barrio que expone el plan de gestión de obras y plan de gestión social comprometido entre las partes con el MINVU y el municipio.

Etapa II Ejecución del contrato de Barrio: Corresponde a la ejecución del Plan de Gestión de Obras y Gestión Social, esta ejecución tiene como principio rector el lograr la mayor participación posible de los vecinos y vecinas, profundizando el vínculo iniciado con ellos, fortaleciendo la confianza, las redes y los liderazgos propios del barrio, esto a través de una dinámica de trabajo conjunto con el CVD en el acompañamiento y monitoreo del Contrato de Barrio, tanto en las obras físicas como sociales.

Etapa III Evaluación y cierre: Actividades relacionadas con la evaluación y cierre del programa, a saber, una evaluación participativa de los productos y resultados del programa, así como la sistematización y formulación de una agenda futura que permita la sostenibilidad del programa.

Este programa fue catalogado por el mismo ministerio como un cambio de paradigma en las políticas urbanas consecuente con el proyecto de integración social de la apuesta del gobierno de Bachelet, así, el Programa Quiero mi Barrio abordaría por primera vez el mejoramiento y la recuperación de la ciudad construida en la dimensión de barrio, basado en el mejoramiento del entorno barrial y el fortalecimiento de la participación ciudadana, como elementos fundamentales de las políticas habitacional y urbana ${ }^{57}$.

Desde el mundo académico también se coincidía con esta visión, siendo el referente obligado la publicación del libro "Los sin techo"58 que planteaba que el problema de la vivienda había cambiado: si antes el problema eran las familias pobres "sin techo", el problema ahora eran las condiciones de las viviendas para los sectores

57 Ministerio de Vivienda y Urbanismo, 2008b.

58 Rodríguez \& Sugranyes, 2005 
pobres, ya que las políticas habitacionales vigentes era deficientes y las viviendas no cumplían con los estándares mínimos para una buena calidad de vida. De ahí se identificaba un punto de inflexión que implicaba reconocer que el stock de vivienda social era un problema, este reconocimiento permitiría pasar de una etapa donde los sin casa tienen techo a una etapa donde la tarea fuera hacer de ese techo una vivienda digna e integrada. Una de las propuestas era justamente la rehabilitación física y social de los conjuntos de vivienda social construidos desde la década de los noventa y mejorar las poblaciones de los años cincuenta y sesenta.

El Programa de Recuperación de Barrios (2010-2014) sigue la misma senda que el anterior, pero con modificaciones relevantes, entre ellas la concursabilidad. Esto implicó que los municipios -autoridades locales- concursan por la asignación de los recursos y el Ministerio de Vivienda y Urbanismo las propuestas a realizar.

El MINVU considera la concursabilidad como una manera de establecer roles más activos por parte de los municipios y los vecinos en el proceso de recuperación de barrios, lo que de acuerdo a la evaluación del ministerio ${ }^{59}$ permite una focalización de la inversión a partir de una selección objetiva de los barrios concursantes, llegando efectivamente a los más vulnerables en términos físicos y sociales, además de posibilitar un mayor compromiso respecto de la intervención y un sentido de pertenencia respecto a la recuperación proyectada. A ello se suma la decisión de establecer un aporte económico tanto de los municipios como de los vecinos, lo que de acuerdo a la misma evaluación tiene por objetivo lograr un mayor compromiso durante el proceso de recuperación y su etapa posterior, asociada al cuidado y mantención de la propia intervención urbana en función de una regeneración sustentable

El resultado de este concurso implicó la selección de 15 nuevos barrios para ingresar al programa el año 2011, para el año 2012 se formaliza el concurso, lanzándose el primer concurso regular de recuperación de barrios lo cual significó el ingreso de 41 nuevos barrios, y el año 2013 la segunda versión donde ingresan 50 más.

Finalmente, el Programa Quiero Mi Barrio II (2014 a la fecha), que mantiene los mismos principios generales de los procesos establecidos a partir del 2011, es decir, la principal vía de incorporación de barrios será a través de un concurso y manteniendo el aporte municipal y vecinal. ${ }^{60}$.

Al día de hoy y de acuerdo a cifras del MINVU ${ }^{61} e n$ casi una década de implementación han sido seleccionados 520 barrios en todo Chile (221 vía concurso), lo cual corresponde aproximadamente a 1 millón de personas beneficiadas, lo que equivale a un 7\% de la población total del país. De éstos, 200 corresponden al Quiero Mi Barrio, 117 al Programa de Recuperación de Barrios y 203 a la segunda parte del Quiero Mi Barrio.

59 Ministerio de Vivienda y Urbanismo, 2014b, p. 36

60 Ministerio de Vivienda y Urbanismo, 2014c

61 Ministerio de Vivienda y Urbanismo, 2015; Ministerio de Vivienda y Urbanismo, 2014a;

Ministerio de Vivienda y Urbanismo, 2014d. 
Cuadro 1: Trayectoria de las políticas de escala barrial post dictatoriales

\begin{tabular}{|c|c|c|c|c|c|c|}
\hline Programa & Fechas & $\begin{array}{c}\text { Gobier- } \\
\text { no }\end{array}$ & $\begin{array}{c}\text { Generación } \\
\text { políticas de } \\
\text { mejora } \\
\text { barrial }\end{array}$ & Objetivo & $\begin{array}{c}\text { Modelo } \\
\text { operativo }\end{array}$ & $\begin{array}{c}\text { Áreas de } \\
\text { intervención }\end{array}$ \\
\hline
\end{tabular}

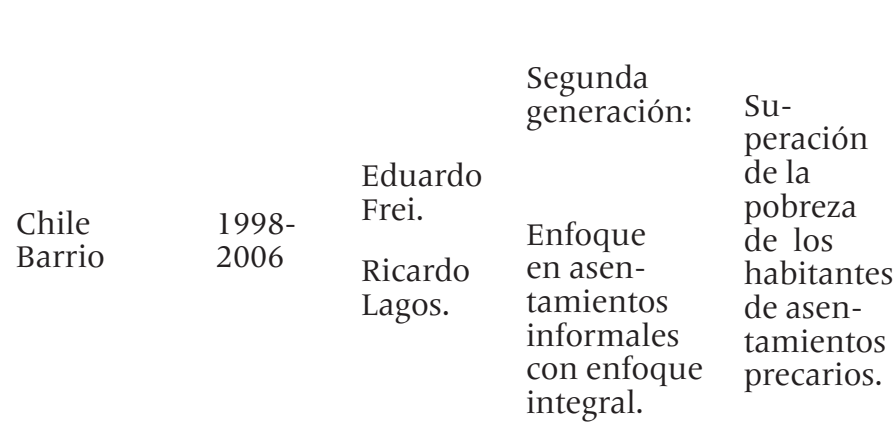

a) Provisión de vivienda social.

b) Fomentar la participación activa de la población del asentamiento en las acciones del programa.

c) Asegurar sustentabilidad del cambio social en los nuevos conjuntos de vivienda social construidos en el marco del programa.

Mejora de la calidad de vida de los habitantes de

Tercera generación: barrios que presentan problemas de dete-

Mejora de conjuntos de vivienda formal.

rioro urbano, segregación y vulnerabilidad social. a) Obras de infraestructura para la mejora del entorno (Plan de gestión de obras)

b) Acciones sociales que contribuyan a fortalecer el tejido social de los barrios (Plan de gestión social)

c) Participación de la comunidad a partir de la conformación del Consejo Vecinal de Desarrollo.
972 asentamientos informales.

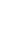

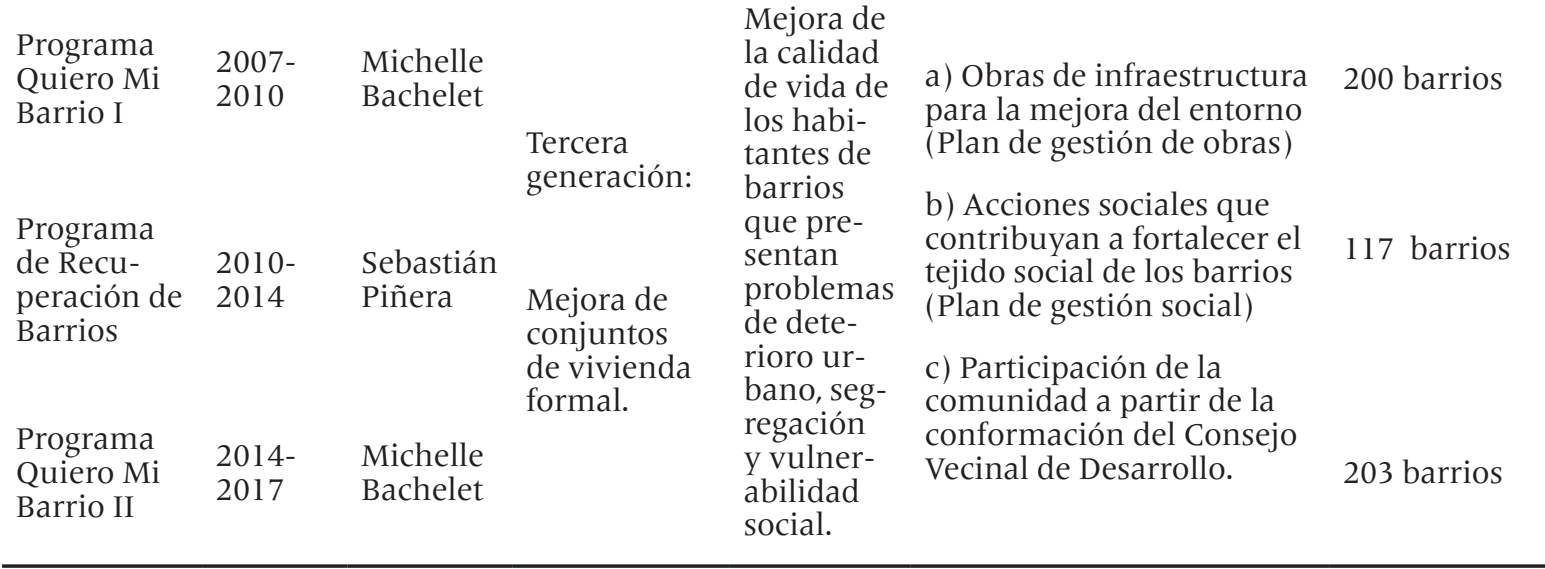

Fuente: Elaboración propia a partir de documentos oficiales.

\section{Políticas urbanas de escala barrial post dictatoriales: claves discursivas}

En coherencia con los lineamientos teóricos propuestos por la Economía Política Cultural el artículo propone la metodología del análisis crítico de discurso en su variante estratégica relacional ${ }^{62}$ para analizar los discursos del Chile neoliberal, específicamente los referidos a la dimensión urbana y la noción de barrio ${ }^{63}$. Además, propone como prioridad debatir el lenguaje de la doctrina neoliberal, especialmente el carácter de inevitable con el cual es presentado, esto pues los gobiernos, pese a las diferencias de escala y orientación política, asumen los procesos de neoliberalización como meros datos cotidianos a lo cual no queda más que plegarse, por lo que

62 Fairclough, 1989, 1993, 2000, 2006a y 2006b.

63 El análisis total contempló un corpus de 15 documentos oficiales de política urbana publicados por el Ministerio de Vivienda y Urbanismo desde el año 1990 a 2013, incluyendo el documento "Propuesta de Vivienda y Desarrollo Urbano. Comisión de vivienda y desarrollo urbano de la concertación democrática" del año 1989 y un corpus de 4 documentos bases de la trayectoria de las políticas urbanas de escala barrial chilenas post dictadura del año 1998 a 2012. Por razones de espacio se presenta aquí el análisis de los documentos bases de las políticas de escala barrial. 
la investigación discursiva permite cuestionar esta naturaleza dada de la reestructuración neoliberal.

La noción de barrio del Programa Chile Barrio está directamente relacionada con el panorama de los asentamientos informales existentes hacia finales de la dictadura, así, el barrio se entiende en un primer momento como la escala de intervención focalizada de las políticas urbanas que permitiría transformar estos asentamientos informales, "campamentos", en asentamientos formales, es decir "barrios". De esta manera la connotación es doble, los campamentos son barrios en potencia, pues son los sectores más pobres de la ciudad, pero al mismo tiempo tienen una serie de atributos que se pueden "rescatar" a partir de la política pública.

La "naturaleza" de estos barrios en potencia -campamentos- es la de "concentrar una proporción significativa de las personas que se encuentran bajo la línea de la pobreza, constituyéndose en uno de los principales bolsones de concentración territorial de pobreza e indigencia"64. La utilización del término "naturaleza" indica la condición dada de estos asentamientos, lo que permite omitir la discusión acerca de las causas estructurales de esta concentración de pobreza y también eliminar de plano la modificación de las políticas públicas urbanas y sociales implementadas en dictadura. Además, se trata de unidades territoriales delimitadas y auto contenidas, donde "el tamaño y densidad de estos asentamientos es muy variable, pudiendo oscilar en un rango de 20 a 400 viviendas precarias" 65 .

Los habitantes de estos barrios "presentan importantes carencias materiales (viviendas inadecuadas, ausencia de servicios básicos como alcantarillado, agua potable, luz eléctrica y accesos irregulares); y, asimismo, estrategias de sobrevivencia precarias y débiles las que se reflejan en la informalidad e inestabilidad en los puestos de trabajo y marginalidad respecto de las oportunidades que ofrece el país"66, es decir, por el hecho de vivir en estos sectores los habitantes tienen ciertas características intrínsecas, las cuales no les permiten acceder a las oportunidades que efectivamente ofrecería el país. En este sentido, el proyecto país efectivamente ofrece las oportunidades por lo que el problema es que este tipo de habitante no tiene las herramientas para poder acceder a ellas, la responsabilidad y el agente de esta acción es el individuo y no el colectivo. El discurso permite afirmar entonces que el problema no es el proyecto país, pues éste sí da las oportunidades, sino que las personas de estos barrios en potencia, recayendo en ellas la responsabilidad última.

El programa Chile Barrio tiene por objetivo "contribuir a través de una acción integrada a la superación de la pobreza de los habitantes de los asentamientos precarios del país, a través de un mejoramiento sustancial de su situación residencial, de la calidad de su hábitat y de sus oportunidades de inserción social y laboral" ${ }^{\prime \prime}$, es decir, el rol del programa es una "contribución" a la superación de la pobreza,

64 Ministerio de Vivienda y Urbanismo, 1998, p. 2

65 Ministerio de Vivienda y Urbanismo, 1998, p. 2

66 Ministerio de Vivienda y Urbanismo, 1998, p. 2

67 Ministerio de Vivienda y Urbanismo, 1998, p. 2 
recurso discursivo que permite intervenir focalizadamente, pero al mismo tiempo derivar responsabilidades de carácter estructural.

De este modo, "se busca complementar y coordinar recursos financieros y capacidades técnicas de ministerios y servicios públicos con los del mundo privado, representando por las organizaciones de la sociedad civil y del ámbito empresarial, de modo de ponerlos a disposición de la población que habita estos asentamientos para concebir proyectos articulados de superación de la pobreza a nivel local"68, es decir, la integralidad está asociada a la apuesta por una gobernanza entre la dimensión pública y privada, donde el ámbito empresarial tiene un rol preponderante en la superación de la pobreza, siempre bajo una noción de lo local restringido a un perímetro y marco de acción definido.

La lógica de convertir los campamentos/barrios en barrios formales está asociado a parámetros definidos sobre lo que es el desarrollo comunitario e inserción social, lo cual descansa en último término en el ímpetu personal, así, uno de los objetivos del programa es "dejar capacidades radicadas en las comunidades de los asentamientos precarios intervenidos para que éstas queden en condiciones para formular y ejecutar iniciativas propias y puedan acceder a los beneficios (servicios y/o programas) de las redes públicas y privadas, en un horizonte temporal mayor a la intervención del Programa Chile-Barrio propiamente tal" ${ }^{69}$. Apelando a la noción de comunidad, el barrio tendría como característica ser depositario de una comunidad que es capaz de pensar y realizar iniciativas propias y de ese modo acceder a los beneficios que están allí esperando a ser utilizados, no se trata de oportunidades que no existen, por el contrario, el discurso articula una narrativa donde las oportunidades y los beneficios efectivamente están y la razón de que estos habitantes no los "aprovechen" es porque no cuentan con las capacidades para lograrlo.

Así, se comprende la denotación de "usuarios" con el cual se cataloga a las personas que habitan estos campamentos, de modo que "los usuarios potenciales del programa son las familias u hogares de los asentamientos consignados en el Catastro Nacional de Asentamientos precarios"70 y "serán usuarios participantes del programa aquellos usuarios potenciales que, además de los anteriores, reúnen las siguientes características: pertenencia a asentamientos precarios respecto de los cuales exista viabilidad técnica y económica para su radicación o erradicación; pertenencia a comunas cuyos Municipios hayan expresado u suscrito los compromisos municipales mínimos para participar institucionalmente en el programa; pertenencia a asentamientos comunitarios cuya comunidad de familias haya suscrito los compromisos y aportes mínimos para participar como usuarios del programa"71. De manera que los "usuarios" deben cumplir una serie de requisitos para poder acceder a ser parte del programa, el discurso del "compromiso" se entiende entonces en el marco de la contención de las posibles tomas de terrenos que se esperaban con el fin

68 Ministerio de Vivienda y Urbanismo, 1998, p. 2

69 Ministerio de Vivienda y Urbanismo, 1998, p. 3

70 Ministerio de Vivienda y Urbanismo, 1998, p. 4

71 Ministerio de Vivienda y Urbanismo, 1998, p. 4 
de la dictadura, preocupación central especialmente en los primeros gobiernos post dictatoriales, así "los usuarios participantes del programa mantendrán su carácter de tales, en la medida que mantengan vigentes sus compromisos, y éstos se vayan cumpliendo dentro de los márgenes de la progresividad pactada"72

Esto coincide con claves discursivas identificadas en documentos de política pública urbana de carácter general, donde se evidencia el borroneamiento del poblador y nacimiento del beneficiario ${ }^{73}$. El poblador como ciudadano que reivindica el derecho a la vivienda digna como una demanda política de justicia social va siendo borrado del discurso, reemplazándose por el beneficiario, el usuario y finalmente el consumidor o cliente. Esto a partir de la noción de la vivienda ya no cómo un derecho, sino que como un patrimonio económico y principal inversión de las familias, así el Estado ayuda a los pobres a obtener un capital vital que es la puerta de salida a la pobreza y al mismo tiempo su visa de entrada al mercado. El esfuerzo y disciplina personal es aquí central, esto a través del mecanismo del ahorro sistemático, prueba del sudor y disposición de los postulantes.

Esto es evidente cuando se declara que "debe recordarse que en los inicios del actual gobierno existía un fuerte déficit habitacional, masivos allegamientos, especialmente en el periodo 1973-1986, con excepción del año 1981. A pesar del alza del número de viviendas construidas a partir de 1987, las expectativas generadas por el nuevo Gobierno, el arrastre señalado y la ausencia de comunicación existente entre los grupos que aspiraban a un techo propio y el Gobierno anterior, hacían presumir una atmosfera de tomas y movimientos viviendistas agresivos". ${ }^{74}$

Este párrafo indica y diferencia aquellos movimientos viviendistas agresivos de aquellos pacíficos, denotando a las tomas de terreno - principal estrategia del movimiento poblador para exigir el derecho a la vivienda- como una acción agresiva y por ende ilegítima. De ahí la necesidad de "un reconocimiento justo a un esfuerzo fructífero"75, en tanto se lograría contener las aspiraciones de corte agresivo de quienes aspiraban a un techo propio.

Todo el sistema se sustenta en la disciplina social respecto a la vivienda, la que hace que el sistema sea exitoso, lo que significa el respeto irrestricto a la vía formal establecida para el acceso a la vivienda, que se basa en el ahorro y el cumplimiento de ciudadanos responsables que cumplen con ello aunque ello signifique dejar de comer. Seguidamente, deslegitima y niega la lucha de décadas del movimiento de los pobladores, al dejar fuera del marco de posibilidad a las estrategias ilegales o informales, es decir, las tomas de terrenos y la reivindicación del derecho a la vivienda, cuestiones que quedan el ámbito de la irresponsabilidad e indisciplina.

Así, en ésta lógica de contención, los programas de recuperación de barrios esperan enfrentar un problema específico: "una de las características que se ha dado

72 Ministerio de Vivienda y Urbanismo, 1998, p. 5

73 Se incluye aquí un importante elemento extraído del análisis de los documentos generales de política urbana por su relevancia para el argumento.

74 Ministerio de Vivienda y Urbanismo, 1994, p. 3

75 Ministerio de Vivienda y Urbanismo, 1994, p. 3 
en la construcción y diseño de las ciudades es la segregación y deterioro urbano, lo que se manifiesta en múltiples problemas, tales como barrios con déficit de servicios básicos, tanto en el acceso como en la calidad de los mismos; barrios con déficit de espacios públicos e infraestructura comunitaria; espacios territoriales con escaza conectividad y deficiente accesibilidad vial y de transporte; barrios con deterioro evidente de sus viviendas, espacios públicos e infraestructura comunitaria, así como la presencia de problemas medio ambientales, como la existencia de microbasurales o fuentes de contaminación"76. La forma verbal de esta descripción permite establecer como punto de partida la segregación y el deterioro urbano que se "ha producido" sin agente y sin responsabilidad, por lo que es un dato de la causa que se debe aceptar. De esta manera el camino del campamento/barrio al barrio del programa Chile Barrio se vuelve a repetir, pero esta vez del barrio vulnerable y segregado al barrio recuperado y rehabilitado, utilizando un lenguaje médico vinculado a la mejoría de una condición de enfermedad.

De esta manera, la segregación y vulnerabilidad social “se evidencian por el débil sentido de pertenencia de los vecinos con su espacio barrial, la estigmatización negativa de ciertos barrios, el deterioro de las relaciones sociales y desconfianza entre los vecinos, la baja organización y participación social, la creciente inseguridad ciudadana, y la concentración de problemas de vulnerabilidad social como drogadicción, microtráfico, delincuencia, etc." ${ }^{77}$. Estos son problemas de los barrios vulnerables y segregados, no de la ciudad en general, de modo que estas dificultades son relevantes en estos barrios específicos y no en el resto de la urbe, donde esto -aunque suceda- no es objeto específico y focalizado de la política urbana, los responsables de estos "males sociales" están así localizados y situados.

Si en el caso del Chile Barrio la localización y situación de los barrios a intervenir fueron establecidos a través de un catastro, en el caso del Programa Quiero Mi Barrio “la selección de barrios se efectuará por el MINVU, aplicando criterios indicadores de deterioro urbano y vulnerabilidad social, los cuales se elaborarán a partir de la experiencia y aplicación del Programa en su primera etapa"78. Así, la noción de barrio se vuelve a establecer como una unidad delimitada y auto contenida, a partir de estos indicadores y una cierta cantidad de viviendas que lo componen.

De esta manera, si el programa Chile Barrio buscaba contribuir a la superación de la pobreza de los habitantes de los asentamientos precarios del país, el Programa Quiero Mi Barrio también tiene por objetivo contribuir, pero esta vez "al mejoramiento de la calidad de vida de los habitantes de barrios que presentan problemas de deterioro urbano y vulnerabilidad social"79. Nuevamente la operación discursiva permite desligarse de la responsabilidad acerca de las causas estructurales de este deterioro urbano y vulnerabilidad social, pero al mismo tiempo declarar su importancia restringida a la acción del Estado en ámbitos delimitados y focalizados en la

76 Ministerio de Vivienda y Urbanismo, 2007, p. 3

77 Ministerio de Vivienda y Urbanismo, 2007, p. 3

78 Ministerio de Vivienda y Urbanismo, 2007, p. 4

79 Ministerio de Vivienda y Urbanismo, 2007, p. 8 
escala barrial. De hecho, el discurso es brutalmente explícito en este sentido: "considerando que en la mayoría de los barrios se concentran múltiples problemáticas sociales como desempleo, pobreza, drogadicción, delincuencia, etc. es importante aclarar que el Programa no pretende asumirlas, sino aportar desde una visión general del deterioro y vulnerabilidad social, con el objetivo de incluir el impacto de estas dimensiones en la propia actuación y derivar a cada sector específico lo que le corresponda abordar"80. De esta manera, la premisa es "que la acción e inversión desarrollada en un territorio definido se focalizará en un trabajo de dinamización de la red social de los vecinos residentes y en la recuperación de espacios de uso colectivo" ${ }^{\prime \prime}$.

En este proceso de focalización, los usuarios/habitantes de los campamentos/ barrios del Programa Chile Barrio, serán ahora los vecinos que habitan los conjuntos de vivienda social, en este marco el programa tiene por objetivo levantar una instancia de organización específica, el Consejo Vecinal de Desarrollo, entendido como "la instancia de participación, coordinación y control local de la ejecución del Programa en el barrio" ${ }^{\prime 2}$. Serán los vecinos quienes tendrán la posibilidad y al mismo tiempo la responsabilidad de trabajar conjuntamente para el mejoramiento del barrio, constituyéndose como una agencia restringida a los requisitos financieros y técnicos, así como las normas establecidas por el programa.

Así, el programa Chile Barrio declaraba superar la pobreza a partir de la formalización de los asentamientos informales, esta formalización fue a partir de la radicación o relocalización de población a conjuntos de vivienda social en la lógica de las políticas urbanas heredadas de la dictadura -básicamente el subsidio a la demanda y la construcción de vivienda social por parte del empresariado- con las consecuencias que ya hemos visto, entre las más relevantes, la ubicación periférica y mala calidad. Posteriormente, los siguientes programas de escala barrial justamente buscarán contener las consecuencias de la pobreza urbana, esta vez de los mismos conjuntos de vivienda social.

Esto significa que la trayectoria de los programas de escala barrial tiene como eje la contención -consuelo, contenedor, control- de las expresiones más agudas de la pobreza urbana, intentando aminorar los conflictos más evidentes derivados de políticas públicas urbanas y sociales iniciadas en dictadura, así, esta contención implica continuidad y al mismo tiempo un fortalecimiento de las políticas públicas neoliberales. La operación es compleja: declarar la lucha contra la pobreza y al mismo tiempo sustentar las bases que la generan, articulación posible a partir de una noción restringida de lo local que erige la escala del barrio como el eje de una solución que llegará en algún momento, al igual que la promesa de la campaña concertacionista: "la alegría ya viene".

80 Ministerio de Vivienda y Urbanismo, 2007, p. 9

81 Ministerio de Vivienda y Urbanismo, 2007, p. 9

82 Ministerio de Vivienda y Urbanismo, 2007, p. 17 


\section{Geografías de la contención: consuelo, contenedor y control}

Los argumentos expuestos fundamentan la propuesta de entender las políticas de escala barrial como procesos de regulación y gobernanza, pues tienen como principal objetivo garantizar el orden social, en consideración de la improbabilidad de la reproducción y expansión del capitalismo. Paradojalmente, este esfuerzo siempre será incompleto y a lo menos frustrante, dada la naturaleza conflictiva del sistema capitalista y los diversos fallos de la gobernanza, es por ello que las políticas urbanas de escala barrial se pueden entender como parte del conjunto de normas, instituciones y políticas que intentan sostener el régimen de acumulación y lograr -siempre de modo transitorio y en marcos espacio temporales específicos- un cierto acuerdo social.

En consecuencia, el protagonismo de las políticas de escala barrial en el curso de la década de los noventa está lejos de ser una casualidad. Por el contrario, en la dinámica de ensayo y error propia de los procesos de neoliberalización, las políticas de escala barrial tienen un rol preponderante para intentar compensar y equilibrar algunos de los efectos problemáticos de la polarización producida por la naturaleza desigual de los procesos de neoliberalización, específicamente la persistente pobreza urbana de las ciudades. Las entendemos entonces como estrategias para intentar aliviar la exclusión social, minimizando, localizando y desplazando los conflictos contribuyendo al mantenimiento de la legitimidad y hegemonía del orden general.

Estos procesos se evidencian en América Latina y específicamente en Chile en el contexto del doble requerimiento de establecer patrones articulados de neoliberalización y la urgencia de enfrentar las tendencias de crisis que para los noventa se hacían evidentes. Las políticas de escala barrial en la región se enmarcan entonces en el giro de las políticas sociales de acuerdo, en la apuesta por la focalización y la retirada políticas públicas de carácter universal, con énfasis en la responsabilidad y participación de la ciudadanía, la comunidad y lo local.

En esta línea, los procesos de selectividad espacial del Estado privilegian la escala barrial como la encarnación de la comunidad y lo local en un sentido restringido, es decir, el barrio como una escala de intervención primordial, pero al mismo tiempo limitada y problemática. Esta noción de barrio permite desplazar, delimitar, situar y confinar los conflictos propios de sociedad y ciudad capitalista neoliberal en ciertas áreas de la ciudad, restringiendo el sentido de lo local y lo comunitario a aquellos sectores donde las contradicciones y desequilibrios inherentes a la lógica capitalista muestran su aspecto menos atractivo, así mismo, en nombre de la participación transfieren responsabilidades a las comunidades, que al mismo tiempo son impotentes ante los marcos regulatorios generales.

Las políticas urbanas de escala barrial se entienden entonces como tecnologías gubernamentales - ensamblajes de conocimientos, racionalidades disciplinarias y gubernamentales, lugares y procesos de intervención calculada y relaciones sociales para transformar la naturaleza y/o gobierno de las relaciones sociales- que permite disciplinar a la población en función de estos objetivos. 
De esta manera, el discurso sobre lo local y comunitario tampoco es una cuestión al azar, se trata de elementos discursivos configurados ideológicamente, en tanto privilegia sentidos y significados coherentes con intereses específicos vinculados al proyecto neoliberal y la lucha por la hegemonía. La evocación al barrio y por esa vía a lo local y lo comunitario -en su sentido restringido- va en la línea de desactivar las socializaciones amenazantes que cuestionan aspectos fundamentales del modelo. Esto es claro en el caso chileno, donde el movimiento poblador fue sistemáticamente desplazado por las diversas políticas urbanas implementadas por los gobiernos post dictatoriales.

Los programas de mejoramiento barrial de la región y específicamente los chilenos permitirán reducir el conflicto que acarrea la pobreza urbana, asegurando estabilidad y gobernabilidad urbana. Estas políticas seguirán entonces el patrón de la focalización, esta vez territorial, en concordancia con el desmantelamiento de los derechos sociales universales; el reemplazo del actor político por un ciudadano individualizado, consumidor, beneficiario o usuario; la configuración de un Estado mediador; finalmente, la evocación del barrio, la comunidad y lo local como responsables (hacia el interior) y al mismo impotentes (hacia el exterior) del desarrollo y bienestar.

Particularmente para el caso chileno, Hidalgo, Alvarado y Santana proponen y fundamentan una hipótesis abre un importante ámbito de investigación futura: la supuesta humanización del neoliberalismo es una estrategia para solucionar las contradicciones de esta ideología, en este contexto, la producción del espacio chileno mediante la provisión, planificación y localización de las viviendas sociales evidencian las acciones correctivas del Estado que han generado y reproducido nuevas prácticas de expoliación y esquilmo.

Así, la política habitacional centrada en los subsidios hacia la demanda expolia a los grupos sociales más pobres despojándolos del acceso a la centralidad y servicios urbanos mediante su expulsión a los bordes de las ciudades e incluso de las regiones urbanas y, por otra parte, esquilma los recursos y bienes comunes que brindan los espacios naturales que son destruidos por la urbanización. De esta manera el Estado genera políticas para cubrir el acceso a la vivienda (corrección), arrojando a los brazos del mercado el lugar donde habitarán quienes obtienen este beneficio, siendo sectores distantes, de alto costo y sin los beneficios asociados a la centralidad (expoliación), al mismo tiempo esta lógica implica procesos de intensa urbanización de la naturaleza (esquilmo) sin alterar los principios ideológicos que sostienen el desarrollo urbano, a saber, propiedad privada y rentabilidad con las conocidas consecuencias de segregación y desigualdades urbanas que acompañan la articulación de atractivos nichos de renta y acumulación inmobiliaria.

En este marco proponemos que existe una especificidad y al mismo tiempo una complementariedad entre las políticas públicas de vivienda social y las políticas de escala barrial: ambas refieren al "rostro humano" del neoliberalismo, la política habitacional orientada a resolver la provisión de vivienda social y las políticas de escala 
barrial a intentar aumentar la satisfacción residencial de los conjuntos de vivienda social. Los autores han explorado esta vinculación en casos de mejoramiento barrial en Santiago y Valparaíso, abriéndose un interesante ámbito de investigación futuro.

En consecuencia, el contenido discursivo de las políticas chilenas de escala barrial es fundamental pues promueven ciertos sentidos y significados coherentes con el proyecto político hegemónico, en el caso de Chile, de continuidad y fortalecimiento del ajuste neoliberal. En función al análisis realizado se propone la figura de la contención para entender el contenido ideológico de las políticas de escala barrial de los gobiernos post dictatoriales chilenos, contención en tres sentidos:

Contención en tanto consuelo. Las políticas de escala barrial post dictatoriales chilenas hacen un llamado a la comunidad y lo local como amortiguadores de los efectos problemáticos del modelo en el contexto de repliegue de las políticas de garantía de derechos sociales y despliegue de la lógica de los beneficiarios de ayudas del Estado. En este marco, los proyectos urbanos y sociales contemplados en las políticas de escala barrial post dictatoriales obviamente significan una contribución al mejoramiento de la calidad de vida de los habitantes beneficiados. El programa Chile Barrio implica consuelo al plantearse como solución habitacional a los habitantes de asentamientos informales, diagnosticados como deficientes, en tanto no cuentan con título de propiedad, no tienen acceso a servicios urbanos básicos y la materialidad de la vivienda es defectuosa. Los programas integrados en la línea de Recuperación de Barrios (Quiero mi Barrio, Recuperación de Barrios y Quiero mi Barrio II) implican mejorar la calidad de vida de barrios deteriorados en términos urbanos, pero también sociales, evidenciando en problemas de espacios públicos deteriorados, imagen ambiental degradada, falta de equipamiento colectivo, débil sentido de pertenencia, estigmatización, inseguridad ciudadana, entre otros problemas.

Contención en tanto contenedor. Las políticas de escala barrial de los gobiernos post dictatoriales permiten enfrentar los temas de pobreza y segregación socio espacial de un modo focalizado y restringido, espacializando en una escala específica contradicciones que como hemos visto son de carácter estructural. Chile Barrio define como ámbito de intervención 972 unidades espaciales, en base a los cuales se solucionaría el problema de los asentamientos informales, la historia se encargaría de demostrar lo errado de esta apuesta. Por su parte, los programas de Recuperación de barrios definen polígonos de intervención igualmente encapsulados: 200 barrios (Quiero mi Barrio); 117 barrios (Programa de Recuperación de Barrios) y 203 barrios (Quiero mi Barrio II).

Finalmente, contención en tanto control de los conflictos y problemas derivados del carácter capitalista de corte neoliberal de las políticas urbanas implementadas a la fuerza en dictadura y fortalecidas por los gobiernos post dictatoriales, lo que se evidencia en el borronamiento del movimiento poblador y sus demandas históricas. Asimismo, esta narrativa asigna importantes responsabilidades a los habitantes a escala local y comunitaria en un marco de impotencia respecto a las reglas del juego generales articulando dispositivos de disciplinamiento y control. 
Chile Barrio se contextualiza para enfrentar el riesgo inminente de tomas de terreno, donde propone una solución habitacional, pero de acuerdo a los sistemas de subsidios pre establecidos; complementariamente, el programa declaraba la participación ciudadana como instancia de aprendizaje y crecimiento personal y comunitario, así, los habitantes "deben percibir - además de ser considerados y sus opiniones acogidas - el efectivo cambio en sus condiciones de vida como un real mejoramiento de sus oportunidades de inserción social y superación de la pobre$\mathrm{za}^{\prime \prime 3}$, cuestión que la trayectoria de las políticas urbana habitacionales se ha encargado de refutar; además, proponía como tercera fase una intervención comunitaria que establecía las dinámicas de convivencia adecuadas a los nuevos conjuntos de vivienda social.

Los programas de Recuperación de Barrios siguen la misma lógica, controlar la violencia, delincuencia y concentración de problemas sociales asociados a la pobreza, segregación y estigmatización de los conjuntos de vivienda social, promoviendo la formación de una instancia de participación y responsabilidad por parte de los habitantes -el Consejo Vecinal de Desarrollo- que si bien tiene ámbitos de decisión, estas están restringidas a la disposición de recursos fijos y condicionados a la normativa del programa. Esto se reforzará con la concursabilidad establecida a partir del año 2011, donde los vecinos serán parte responsable de postulación e incluso están obligados a disponer de recursos para poder ser beneficiarios del programa, esto con el objetivo de garantizar el compromiso y el sentido de pertenencia de los habitantes con el programa.

En síntesis, proponemos explorar las políticas de escala barrial en el caso chileno en relación a la figura de la contención en tres sentidos: como consuelo ante los efectos negativos de las políticas habitacionales, intentando aliviar los efectos de vivir en la periferia; como contenedor al producir un tipo de espacio concreto, a saber, el barrio como unidad espacial delimitada asociado a una comunidad particular que compite con otras por los beneficios del Estado en coherencia a los principios de focalización del Estado subsidiario; finalmente, como medio de control de conflictos actuales o potenciales, fundamentalmente pobreza, violencia, delincuencia o movimientos contestatarios.

\section{Bibliografía}

ADELANTADO, José and SCHERER, Elenise. Desigualdad, democracia y políticas sociales focalizadas en América Latina. Revista chilena de administración pública, 2008, nº.11, p. 117-134.

ALONSO, Luis. Ciudadanía, sociedad del trabajo y Estado de bienestar: los derechos sociales en la era de la fragmentación. Ciudadanía y democracia. Madrid: Pablo Iglesias, 2000.

83 Ministerio de Vivienda y Urbanismo, 2010, p. 23 
ANDERSSON, Roger and MUSTERD, Sako. What Scale Matters? Exploring the Relationships Between Individuals' Social Position, Neighbourhood Context and the Scale of Neighbourhood. Geografiska Annaler: Series B, Human Geography, 2010, vol. 92, no. 1, p. 23-43.

ANDERSSON, Roger and MUSTERD, Sako. Area-Based Policies: A Critical Appraisal. Tijdschrift voor economische en sociale geografie, 2005, vol. 96, no. 4, p. 377-389.

ARRIAGADA, Camilo. Segregación socioespacial y reconfiguración urbana: revisión del concepto, tendencias y propuesta política. Chile urbano hacia el siglo XXI: investigaciones y reflexiones de politica urbana desde la Universidad de Chile. Chile: Universitaria, 2014, p.79-87

ATKINSON, Rowland;DOWLING,RobynyMCGUIRK,Pauline.Home/Neighbourhood/ City/+. Environment and planning A, 2009, vol. 41, n. 12, p. 2816-2822.

ATKINSON, Rob. European urban policies and the neighbourhood: an overview. Proceedings of the ICE-Urban Design and Planning, 2008, vol. 161, no. 3, p. 115122.

ATKINSON, Rob. Combating social exclusion in Europe: The new Urban Policy Challenge. Urban studies, 2000, vol. 37, n. 5-6, p. 1037-1055.

BRENNER, Neil. Urban governance and the production of new state spaces in western Europe, 1960-2000. Review of International Political Economy, 2004, vol. 11, n. 3, p. 447-488.

BRENNER, Neil; PECK, Jamie y THEODORE, Nik. ¿Y después de la neoliberalización? Estrategias metodológicas para la investigación de las transformaciones regulatorias contemporáneas. Urban, 2011 , vol. 1, nº 1, p. 21-40.

BRENNER, Neil; PECK, Jamie y THEODORE, Nik. Urbanismo neoliberal: La ciudad y el imperio de los mercados. Temas sociales, 2009, vol. 66, p. 1-11.

CASTELLS, Manuel. Movimientos de pobladores y lucha de clases en Chile. Revista EURE - Revista de Estudios Urbano Regionales, 1973, vol. 3, nº 7.

CASTILLO, María José. Competencias de los pobladores: potencial de innovación para la política habitacional chilena. Revista INVI, 2014, vol. 29, n. 81, p. 79-112.

CASTILLO, María. Producción y gestión habitacional de los pobladores. Articulación con la politica de vivienda y barrio. Trayectoria y problemática actual. Tesis para optar al grado de doctora en Arquitectura y Urbanismo. Madrid: Universidad Politécnica de Madrid, 2013.

CHATEAU, Jorge. Espacio y poder: Los pobladores. Chile: Facultad Latinoamericana de Ciencias Sociales, 1987.

De la MAZA, Gonzalo. Tan lejos tan cerca: politicas públicas y sociedad civil en Chile. Chile: Lom Ediciones, 2005.

De la MAZA, Gonzalo. Políticas públicas y sociedad civil en Chile: el caso de las políticas sociales (1990-2004). Política, 2004, vol.43, p. 105-148. 
DIETZ, Robert D. The estimation of neighborhood effects in the social sciences: An interdisciplinary approach. Social Science Research, 2002, Vol. 31, no. 4, p. 539575.

DIRECCIÓN DE PRESUPUESTOS. GOBIERNO DE CHILE. Evaluación de Impacto Programa Chile Barrio, 2007.

DIRECCIÓN DE PRESUPUESTOS. GOBIERNO DE CHILE. Informe final programa de mejoramiento de barrios, 2012.

FAIRCLOUGH, Norman. Language and globalization. Abingdon, OX; New York, NY: Routledge, 2006a.

FAIRCLOUGH, Norman. Discourse and social change. Cambridge: Polity press, 2006b.

FAIRCLOUGH, Norman. Representaciones del cambio en el discurso neoliberal. Cuadernos de relaciones laborales, 2000, $\mathrm{n}^{\circ}$. 16, p. 13-36.

FAIRCLOUGH, Norman. Discourse and social change. Cambridge: Wiley, 1993.

FAIRCLOUGH, Norman. Language and power. Londres: Longman, 1989.

FERNÁNDEZ, Raúl. La agenda global y la gestión local del hábitat. Documentos desarrollo local en áreas metropolitanas. Universidad Nacional de General Sarmiento, 2001.

FORREST, Ray. Who cares about neighbourhoods? International Social Science Journal, 2008, vol. 59, n. 191, p. 129-141.

FORREST, Ray y KEARNS, Ade. Social Cohesion, Social capital and the neighbourhood. Urban studies, 2001, vol. 38, $\mathrm{n}^{\circ}$. 12, p. 2125-2143.

FOUCAULT, Michel. Nacimiento de la biopolitica: Curso del Collège de France (19781979). Buenos Aires: Fondo de cultura económica, 2012.

FOUCAULT, Michel. Vigilar y castigar: nacimiento de la prisión. Madrid: 2000.

FOUCAULT, Michel. Estrategias de poder. Obras esenciales. Barcelona: Paidós, 1999.

FOUCAULT, Michel. La verdad y las formas jurídicas. Barcelona: Gedisa, 1996.

FRENCH, Ricardo; LÓPEZ, Ernesto y ARRIAGADA, Camilo. Crecimiento desigual económico y urbano: desafíos de políticas pro equidad para las ciudades de las próximas décadas. En LÓPEZ, Ernesto; ARRIAGADA, Camilo; JIRÓN, Paola; ELIASH, Humberto.Chile urbano hacia el siglo XXI: investigaciones y reflexiones de politica urbana desde la Universidad de Chile. Chile: Universitaria, 2014, p. 149168.

GARCÉS, Mario. Tomando su sitio: El movimiento de Pobladores de Santiago, 1957-1970. Santiago de Chile: LOM ediciones, 2002.

GARCÉS, Mario. Los pobladores durante la unidad popular: movilizaciones oportunidades políticas y la organización de las nuevas poblaciones. Tiempo histórico: revista de la Escuela de Historia, 201 1, nº 3, p. 37-53.

GARRETÓN, Manuel. Neoliberalismo corregido y progresismo limitado: Los gobiernos de la Concertación en Chile, 1990-2010. Santiago de Chile: Arcis Clacso Prospal, 2012. 
GARRETÓN, Manuel. Transformación de la matriz sociopolítica y desarrollo en Chile. Diplomacia, Estrategia y Política, 2009, n. 9, p. 45-71.

GARRETÓN, Manuel. Politica y sociedad entre dos épocas: América Latina en el cambio del siglo. Rosario, Argentina: Homo Sapiens Ediciones, 2000a.

GARRETÓN, Manuel. Igualdad, ciudadanía y actores en las políticas sociales. Política social: vínculo entre Estado y sociedad. San José, Costa Rica: Universidad de Costa Rica, 2000b.

GOEDE, Marieke. International Political Economy and Poststructural Politics. Basingstoke: Palgrave Macmillan, 2006.

GOUGH, Jamie. Neoliberalism and socialisation in the contemporary city: Opposites, complements and instabilities. Antipode, 2002, vol. 34, n. 3, p. 405-426.

GRAMSCI, Antonio. Antología. México D.F: 1988.

GRAMSCI, Antonio. Notas sobre maquiavelo, sobre la politica y sobre el Estado moderno. Buenos Aires: Nueva visión, 1980

GREZ, Sergio. Bicentenario en Chile. La celebración de una laboriosa construcción política. Historia y comunicación social, 201 1, vol. 16, p. 69-86.

GUROVICH, Alberto. El desarrollo del paradigma neoliberal en la experiencia urbanística chilena. En LÓPEZ, Ernesto; ARRIAGADA, Camilo; JIRÓN, Paola; ELIASH, Humberto.Chile urbano hacia el siglo XXI: investigaciones y reflexiones de politica urbana desde la Universidad de Chile. Chile: Universitaria, 2014.

HARVEY, David. The new urbanism and the communitarian trap. Harvard Design Magazine, 1997, vol. 1, n. 3, p. 68-69.

HARVEY, David. Breve historia del neoliberalismo. Madrid: Ediciones AKAL, 2007.

HIDALGO, Rodrigo. La vivienda social en Chile: La acción del Estado en un siglo de planes y programas. Scripta Nova revista electrónica de geografía y ciencias sociales, 1999, vol. 3, $\mathrm{n}^{\circ} .45$.

HIDALGO, Rodrigo; ALVARADO, Voltaire ; SANTANA, Daniel. Los expulsados de la metrópoli: expolio y esquilmo en la locación de la vivienda social en la ciudad neoliberal. Una perspectiva de Santiago y Valparaíso. Estudios Socioterritoriales, 2006, vol. 20, p. 41-55

HIDALGO, Rodrigo; ALVARADO, Voltaire ; SANTANA, Daniel. La espacialidad neoliberal de la producción de vivienda social en las áreas metropolitanas de Valparaíso y Santiago ( 1990-2014): ¿hacia la construcción idelógica de un rostro humano? Cadernos Metrópole, 2017, vol. 19, n³ 39, pp. 513-535.

HIDALGO, Rodrigo; SANTANA, Daniel; ALVARADO, Voltaire. Mitos, ideologías y utopías neoliberales de la producción del espacio: hacia una agenda de investigación alternativa. En HIDALGO, Rodrigo; SANTANA, Daniel; ALVARADO, Voltaire; ARENAS, Federico; SALAZAR, Alejandro; VALDEBENITO, Carlos; ÁLVAREZ. En las costas del neoliberalismo: planificación, privatización y segunda residencia. Santiago: Instituto de Geografía, Pontificia Universidad Católica de Chile, 2016, p. 24-66. 
INSTITUTO DE LA VIVIENDA. FACULTAD DE ARQUITECTURA Y URBANISMO. UNIVERSIDAD DE CHILE. Catastro de Campamentos y Asentamientos Irregulares, 1997.

INZULZA, Jorge. Complejidad y contradicción entre la política urbana y su (des) articulación con los instrumentos de planificación territorial. En LÓPEZ, Ernesto; ARRIAGADA, Camilo; JIRÓN, Paola; ELIASH, Humberto.Chile urbano hacia el siglo XXI: investigaciones y reflexiones de politica urbana desde la Universidad de Chile. Chile: Universitaria, 2014, p.58-64.

JESSOP, Robert. Cultural political economy and critical policy studies. Critical policy studies, 2010, vol. 3, n. 3-4, p. 336-356.

JESSOP, Robert. El futuro del estado capitalista. Madrid: Los libros de la catarata, 2008. JESSOP, Robert. From micro-powers to governmentality: Foucault's work on statehood, state formation, statecraft and state power. Political geography, 2007, vol. 26, $\mathrm{n}^{\circ} .1$, p. 34-40.

JESSOP, Robert. Critical semiotic analysis and cultural political economy. Critical discourse studies, 2004, vol. 1, n. 2, p. 159-174.

JESSOP, Robert; BRENNER, Neil y JONES, Martin. Theorizing sociospatial relations. Environment and planning D: Society and space, 2008, vol. 26, n. 3, p. 389-401.

JESSOP, Robert y SUM, Ngai-Ling. Beyond the regulation approach: Putting capitalist economies in their place. Cheltenham, UK: Edward Elgar Publishing, 2006.

JIRÓN, Paola y MANSILLA, Pablo. Las consecuencias del urbanismo fragmentador en la vida cotidiana de habitantes de la ciudad de Santiago de Chile. EURE (Santiago), 2014, vol. 40, n. 121, p. 5-28.

KEARNS, Ade y PARKINSON, Michael. The significance of neighbourhood. Urban studies, 2001, vol. 38, n. 12, p. 2103-2110.

KENNETT, Patricia y FORREST, Ray. The Neighbourhood in a european context. Urban studies, 2006, vol. 43, $\mathrm{n}^{\circ}$.4, p. 713-718.

LARENAS, Jorge. ¿Es posible promover la integración social sin política urbana? Diagnóstico y reflexiones. En LÓPEZ, Ernesto; ARRIAGADA, Camilo; JIRÓN, Paola; ELIASH, Humberto.Chile urbano hacia el siglo XXI: investigaciones $y$ reflexiones de politica urbana desde la Universidad de Chile. Chile: Universitaria, 2014, p.257-265

LECHNER, Norbert. Estado y sociedad en una perspectiva democrática. Polis. Revista Latinoamericana, 2003, vol. 2, nº. 6, p. 1-12.

LÓPEZ, Ernesto. Desarrollo inmobiliario, mercado de suelo y exclusión social en áreas metropolitanas chilenas. En LÓPEZ, Ernesto; ARRIAGADA, Camilo; JIRÓN, Paola; ELIASH, Humberto. Chile urbano hacia el siglo XXI: investigaciones y reflexiones de politica urbana desde la Universidad de Chile. Chile: Universitaria, 2014, p. 
LÓPEZ, Ernesto; ARRIAGADA, Camilo; JIRÓN, Paola y ELIASH, Humberto. Chile urbano hacia el siglo XXI: investigaciones y reflexiones de politica urbana desde la Universidad de Chile. Santiago de Chile: Universitaria, 2014.

MARGARIT, Daisy. El sentido del bienestar en una política social de vivienda: el caso de la fase piloto del Chile Barrio. Scripta Nova: Revista electrónica de geografía y ciencias sociales, 2003, vol. $7, \mathrm{n}^{\circ} 146$.

MINISTERIO DE VIVIENDA Y URBANISMO. Cuenta pública presidencial 21 de Mayo. Informe sectorial Ministerio de Vivienda y Urbanismo, 2015.

MINISTERIO DE VIVIENDA Y URBANISMO. Balance 2014 Proyecciones 2015, 2014 a.

MINISTERIO DE VIVIENDA Y URBANISMO. La recuperación de barrios a lo largo de Chile, Ministerio de Vivienda Y Urbanismo, 2014b.

MINISTERIO DE VIVIENDA Y URBANISMO. Lineamientos generales del concurso Programa recuperación de barrios 2014 - 2018, 2014c.

MINISTERIO DE VIVIENDA Y URBANISMO. Medida 27 A Detalle, 2014d.

MINISTERIO DE VIVIENDA Y URBANISMO. Programa Chile Barrio. De medida de emergencia a política pública, 2010.

MINISTERIO DE VIVIENDA Y URBANISMO. Programa Quiero Mi Barrio. Taller Programas de Mejoramiento de Barrios. Análisis Comparado de Lecciones Aprendidas y Nuevos Enfoques, 2008a.

MINISTERIO DE VIVIENDA Y URBANISMO. Resolución 4119 Aprueba manual de procedimientos del Programa de Recuperación de Barrios, 2008b.

MINISTERIO DE VIVIENDA Y URBANISMO. Manual de procedimientos del Programa de Recuperación de Barrios, 2007.

MINISTERIO DE VIVIENDA Y URBANISMO. Chile: un siglo de politicas en vivienda y barrio. Santiago, Chile: Ministerio de Vivienda y Urbanismo, Gobierno de Chile, 2004.

MINISTERIO DE VIVIENDA Y URBANISMO. Orientaciones generales del programa Chile Barrio, 1998.

MINISTERIO DE VIVIENDA Y URBANISMO. 1990-1994: 4 años de gestión. Hacia una politica urbana de vivienda eficiente y equitativa, 1994.

MOLYNEUX, Maxine. Ciudadanía y política social en perspectiva comparada. Política social: vínculo entre Estado y sociedad. San José, Costa Rica: Universidad de Costa Rica, 2000.

MORRIS, Roberto. Successful Approaches to National Slum Upgrading and Prevention. Case of Chile. Santiago: Joint Work Program of the World Bank (WBI), Cities Alliance (CA), United Nations Human Settlements Program (UNHABITAT), Deutsche Gesellschaft für Internationale Zusammenarbeit (GIZ), and InterAmerican Development Bank, 2012

OECD. Urban Policy Reviews, Chile 2013. París: Organisation for Economic Cooperation and Development, 2013. 
PECK, Jamie y TICKELL, Adam. Neoliberalizing Space. Antipode, 2002, vol. 34, $\mathrm{n}^{\circ} .3$, p. 380-404.

PUELLO-SOCARRÁS, José. Neoliberalismo, Antineoliberalismo y Nuevo neoliberalismo. Episodios y trayectorias económico-políticas Suramericanas (1973-2015). En ROJAS, Luis. Neoliberalismo en América Latina. Crisis, tendencias $y$ alternativas. Buenos Aires: Consejo Latinoamericano de Ciencias Sociales (CLACSO), 2015, p. 19-42

PROGRAMA DE LAS NACIONES UNIDAS PARA EL DESARROLLO. Desarrollo humano en Chile: bienestar subjetivo, el desafío de repensar el desarrollo, 2012, Chile: PNUD, 2012.

PROGRAMA DE LAS NACIONES UNIDAS PARA EL DESARROLLO. Desarrollo Humano en Chile: Los tiempos de la politización, Chile: PNUD, 2015.

RIBERA, Ramon. From urban political economy to cultural political economy: rethinking culture and economy in and beyond the urban. Progress in human geography, 2009, vol. 33, $\mathrm{n}^{\circ} .4$, p. 447-465.

RODRÍGUEZ, Alfredo y RODRÍGUEZ, Paula. Políticas neoliberales en Santiago de Chile: políticas contra la ciudad (experiencias latinoamericanas). Questiones Urbano Regionales. revista del instituto de la ciudad, 2013, vol. 2, n . 2, p. 9-28.

RODRÍGUEZ, Alfredo; SUGRANYES, Ana. El problema de vivienda de los «con techo». EURE, 2004, vol. 30, n91, p. 53-65

RODRÍGUEZ, A.; SUGRANYES, A. Los con techo. Un desafío para la política de vivienda social. Santiago: Sur, 2005

ROJAS, Eduardo. Construir Ciudades: Mejoramiento de barrios y calidad de vida urbana. Washington: Banco Interamericano de Desarrollo, 2009.

RUIZ-TAGLE, Javier. Segregación residencial, guetos y políticas de dispersión. En LÓPEZ, Ernesto; ARRIAGADA, Camilo; JIRÓN, Paola; ELIASH, Humberto.Chile urbano hacia el siglo XXI: investigaciones y reflexiones de politica urbana desde la Universidad de Chile. Chile: Universitaria, 2014, p.

RUIZ-TAGLE, Javier y LÓPEZ, Ernesto. El estudio de la segregación residencial en Santiago de Chile: revisión crítica de algunos problemas metodológicos y conceptuales. EURE (Santiago), 2014, vol. 40, n. 119, p. 25-48.

SABATINI, Francisco; CÁCERES, Gonzalo y CERDA, Jorge. Segregación residencial en las principales ciudades chilenas: Tendencias de las tres últimas décadas y posibles cursos de acción. EURE (Santiago), 2001, vol. 27, no. 82, p. 21-42.

SABORIDO, Marisol. El Programa Chile Barrio: lecciones y desafíos para la superación de la pobreza y la precariedad habitacional. Santiago: Comisión Económica para América Latina y el Caribe y Cooperación Italiana, 2005.

SANTISO, Carlos. Gobernabilidad democrática y reformas económicas de segunda generación en América Latina. Instituciones y desarrollo, 2001, vol. 8, p. 325-366. SEPÚLVEDA, Rubén. Progresividad residencial : un estudio sociofísico del programa de mejoramiento de barrios. Santiago: Instituto de la Vivienda, Universidad de Chile, 1994. 
SUM, Ngai-Ling y JESSOP, Bob. Towards a Cultural Political Economy: Putting culture in its place in political economy. Northampton, MA: Edward Elgar Pub, 2013.

VALENZUELA, Iván. Economía Política Cultural: Una nueva propuesta teórica para el estudio de la economía y la cultura. Polis. Revista latinoamericana, 2014, vol. 39, p. 2-17.

WARF, Barney y ARIAS, Santa. The spatial turn: Interdisciplinary perspectives. New York: Taylor \& Francis, 2008.

(C) Copyright: Verónica Tapia Barria, 2018

(c) Copyright Scripta Nova, 2018.

Ficha bibliográfica:

TAPIA BARRIA, Verónica.Geografías de la contención: el rol de las políticas de escala barrial en el Chile neoliberal. Scripta Nova. Revista Electrónica de Geografía y Ciencias Sociales. [En línea]. Barcelona: Universidad de Barcelona, 15 de junio de 2018, vol. XXII, nº 592. ISSN: 1138-9788. 